\title{
Effects of 4D-Var Data Assimilation Using Remote Sensing Precipitation Products in a WRF Model over the Complex Terrain of an Arid Region River Basin
}

\author{
Xiaoduo Pan ${ }^{1,2}$, Xin Li ${ }^{1,3, *}$, Guodong Cheng ${ }^{1,4}$ and Yang Hong ${ }^{5}$ \\ 1 Key Laboratory of Remote Sensing of Gansu Province, Cold and Arid Regions Environmental and \\ Engineering Research Institute, Chinese Academy of Sciences, Lanzhou 730000, China; \\ panxiaoduo@lzb.ac.cn (X.P.); gdcheng@lzb.ac.cn (G.C.) \\ 2 Heihe Remote Sensing Experimental Research Station, Cold and Arid Regions Environmental and \\ Engineering Research Institute, Chinese Academy of Sciences, Lanzhou 730000, China \\ 3 CAS Center for Excellence in Tibetan Plateau Earth Sciences, Beijing 100101, China \\ 4 Institute of Urban Development, Shanghai Normal University, Shanghai 200234, China \\ 5 Department of Hydraulic Engineering, Tsinghua University, Beijing 10084, China; \\ hongyang@tsinghua.edu.cn \\ * Correspondence: lixin@lzb.ac.cn; Tel.: +86-931-4967-249
}

Received: 23 June 2017; Accepted: 14 September 2017; Published: 17 September 2017

\begin{abstract}
Individually, ground-based, in situ observations, remote sensing, and regional climate modeling cannot provide the high-quality precipitation data required for hydrological prediction, especially over complex terrains. Data assimilation techniques can be used to bridge the gap between observations and models by assimilating ground observations and remote sensing products into models to improve precipitation simulation and forecasting. However, only a small portion of satellite-retrieved precipitation products assimilation research has been implemented over complex terrains in an arid region. Here, we used the weather research and forecasting (WRF) model to assimilate two satellite precipitation products (The Tropical Rainfall Measuring Mission: TRMM 3B42 and Fengyun-2D: FY-2D) using the 4D-Var data assimilation method for a typical inland river basin in northwest China's arid region, the Heihe River Basin, where terrains are very complex. The results show that the assimilation of remote sensing precipitation products can improve the initial WRF fields of humidity and temperature, thereby improving precipitation forecasting and decreasing the spin-up time. Hence, assimilating TRMM and FY-2D remote sensing precipitation products using WRF $4 \mathrm{D}-$ Var can be viewed as a positive step toward improving the accuracy and lead time of numerical weather prediction models, particularly over regions with complex terrains.
\end{abstract}

Keywords: TRMM; FY-2D; GPM; data assimilation; inland river basin

\section{Introduction}

Precipitation plays an indispensable role in global and regional hydrological cycles [1,2]. However, it is currently difficult to develop an accurate precipitation product with high spatiotemporal resolution at the watershed scale for complex terrains using solely the traditional ground-based observations, remote sensing products, or regional climate modeling $[3,4]$.

Traditional ground-based observations include rain gauge, disdrometers and radar. Rain gauge is well known to underestimate precipitation because of the uncertainty in precipitation measurement resulting from blockage of the airflow, the saturation effect, evaporation losses and wind-induced losses [5]. Furthermore, the cost and difficulty of setting up or maintaining very dense observational networks over a complex terrain are much higher than for flat regions; thus, the poor point-to-area representativeness and sparse distribution of rain gauges over a complex terrain limit the development 
of accurate precipitation products with high spatiotemporal resolution at watershed-scale. The limitations of rain gauge are also exit for disdrometers and radar. Radar is also known to have high reflectivity with beam blockage caused by the terrain in mountainous regions, which hinders its application to complex regions.

Because of the sparse distribution of rain gauges and the limited coverage of ground-based disdrometers and radar stations, satellite-retrieved precipitation has become one of the major sources of rainfall observations, especially in global studies. Since the first satellite-derived precipitation observations were made in the 1970s [6], various hydrological and meteorological satellites have provided large quantities of valuable weather and climate data. A number of techniques have been developed to estimate precipitation from visible and/or infrared satellite observations based on the concept that cold/bright clouds are related to convection and are likely to produce rain. However, the limitations of visible/infrared precipitation estimation in deciphering the nonlinear inverse relationship between cold cloud tops and surface precipitation, the relatively coarse resolutions of microwave remote sensing of precipitation, which fail to characterize the heterogeneity of complex mountainous regions, and the cascading uncertainties of merged, multifrequency satellite precipitation products have restricted the application of remote sensing precipitation products at the watershed scale to complex terrains.

Numerical simulation can provide a consistent spatial and temporal precipitation product with high spatial-temporal resolution. Generally, global climate models are limited by the computer power with 100-300 km spatial resolution. Regional climate models provided initialization and boundary conditions by global climate models yield much finer spatial resolutions based on 1-50 km spatial resolution. However, precipitation is considered the most difficult parameter to simulate in numerical models because our understanding of precipitation phenomena is not sophisticated enough [7-9]. Because of the considerable randomness of precipitation at both the spatial and temporal scales, the quality of precipitation data simulated using atmospheric models is far worse than the quality of other atmospheric elements, especially over complex terrains.

Therefore, it is of critical importance to integrate in situ and remote sensing observations, as well as RCMs, to improve the predictability of precipitation.

Data assimilation, as a method for incorporating observations into a model of a real system, is considered a key approach to improving the prediction of precipitation [10]. Rainfall is considered as a synthetic variable including the atmospheric information in terms of humidity, temperature, and winds and also contributing to the model atmospheric energy budget [11], so rainfall assimilation is considered as one of the important approaches to improve the weather forecasts. Assimilating precipitation products can yield more accurate initial and boundary conditions for numerical weather predictions (NWPs), with the greatest impacts on water vapor and cloud hydrometeorological mixing ratios in the middle and upper troposphere [12-14]. Županski and Mesinger [15] were the first to assimilate precipitation data in an NWP model. Many other studies have shown that the assimilation of precipitation observations in climate models can improve the NWP simulating capabilities at the global scale [16-20] and at the continental scale [15,21-26]. However, few studies on precipitation assimilation aim to produce high spatiotemporal precipitation products over complex terrains at the regional scale.

Therefore, based on the abovementioned analysis, high-resolution precipitation forecasting for a complex terrain via the assimilation of precipitation observations into NWPs is still rare. Here, we simulate precipitation with $5 \mathrm{~km}$ spatial and $1 \mathrm{~h}$ temporal resolution by assimilating the Tropical Rainfall Measuring Mission (TRMM) and Fengyun-2D (FY-2D) satellite-derived precipitation products into weather research and forecasting (WRF) model for the Heihe River Basin (HRB), an inland river basin located in both arid and semi-arid regions, where complex terrain is prominent: the latitudes distribute from $5000 \mathrm{~m}$ to $800 \mathrm{~m}$, the landscapes from glacier to glacier, the annual precipitation volume fluxes from $1000 \mathrm{~mm}$ to $40 \mathrm{~mm}$, where the intense land-air interaction has strong effect on water and energy exchange between land surface and atmosphere, and over where precipitation, as the 
main scare water resource input, is the key factor to determine the population supporting capacity of land resources.

Therefore, the purpose of this study is to assimilate precipitation data derived from multisatellite remote sensing into a WRF model via four-dimensional variational (4D-Var) data assimilation to improve precipitation forecasting for an inland river basin with a complex mountainous region. This work will be regarded as a guide for producing high spatiotemporal precipitation gridded data for complex terrains via merging traditional observational data, remote sensing data and numerical models.

The next section describes the WRF model configuration, assimilation methodology, and experimental design. The remote sensing-derived precipitation products, including TRMM and FY-2D, are introduced in Section 2. The results are shown in Section 3 and discussed in Section 4, and conclusions are drawn in Section 5.

\section{Methods and Data}

\subsection{Research Region and Data}

The study area is the Heihe River Basin (HRB), which is regarded as an ideal test bed and field laboratory for land surface or hydrological experiments. The HRB originates from glacial melt water and precipitation in the Qilian Mountains, and flows through the provinces of Qinghai, Gansu and Inner Mongolia. It can be divided into three parts: the upper reaches, with elevations ranging 2000-5500 $\mathrm{m}$ and precipitation ranging $250-500 \mathrm{~mm}$; the middle reaches, with elevations ranging 1000-2000 m and precipitation ranging 100-250 mm; and the lower reaches, with elevations of less than $1000 \mathrm{~m}$ and precipitation of less than $100 \mathrm{~mm}$. From the upper reaches to the lower reaches, glacier, permafrost, oasis, bare and Gobi desert areas are distributed. The diverse landscape makes the Heihe River Basin an ideal watershed for scientific research. Comprehensive experiments including Heihe Basin Field Experiment (HEIFE) [27], Watershed Allied Telemetry Experimental Research (WATER) [28] and Heihe Watershed Allied Telemetry Experimental Research (HiWATER) [29] have been conducted in the HRB.

The observational data used to evaluate the results of WRF data assimilation included the precipitation observations recorded at national meteorological stations and nine sets of HOBO rain gauge data provided by the WATER project [28]. The HOBO rain gauges were established to provide reference data and determine the relationships between the measured rainfall rate and raindrop size based on Doppler radar and to evaluate Doppler radar data assimilation in the WRF models and remote sensing data assimilation in the WRF 4D-Var. The date 21 June 2008 was selected as the analysis date for this study. Prior to this time, the $\mathrm{HOBO}$ rain gauges were set to collect rainwater, and it rain fell heavily during and after the analysis date. The gauges are named R01, R02, . , and R09, the exact location of these gauges refer to the Figure 1 of reference [30].

Note that the rain gauge observations have inherent uncertainties, which include random and systematic errors due to wind, wetting, evaporation, and splashing. Errors are larger at higher wind speeds, at which the gauge-observed rainfall rate is generally lower than the actual rainfall rate by $2-18 \%$. Therefore, these rainfall data have been corrected according to the method used by Pan et al. [8]. 


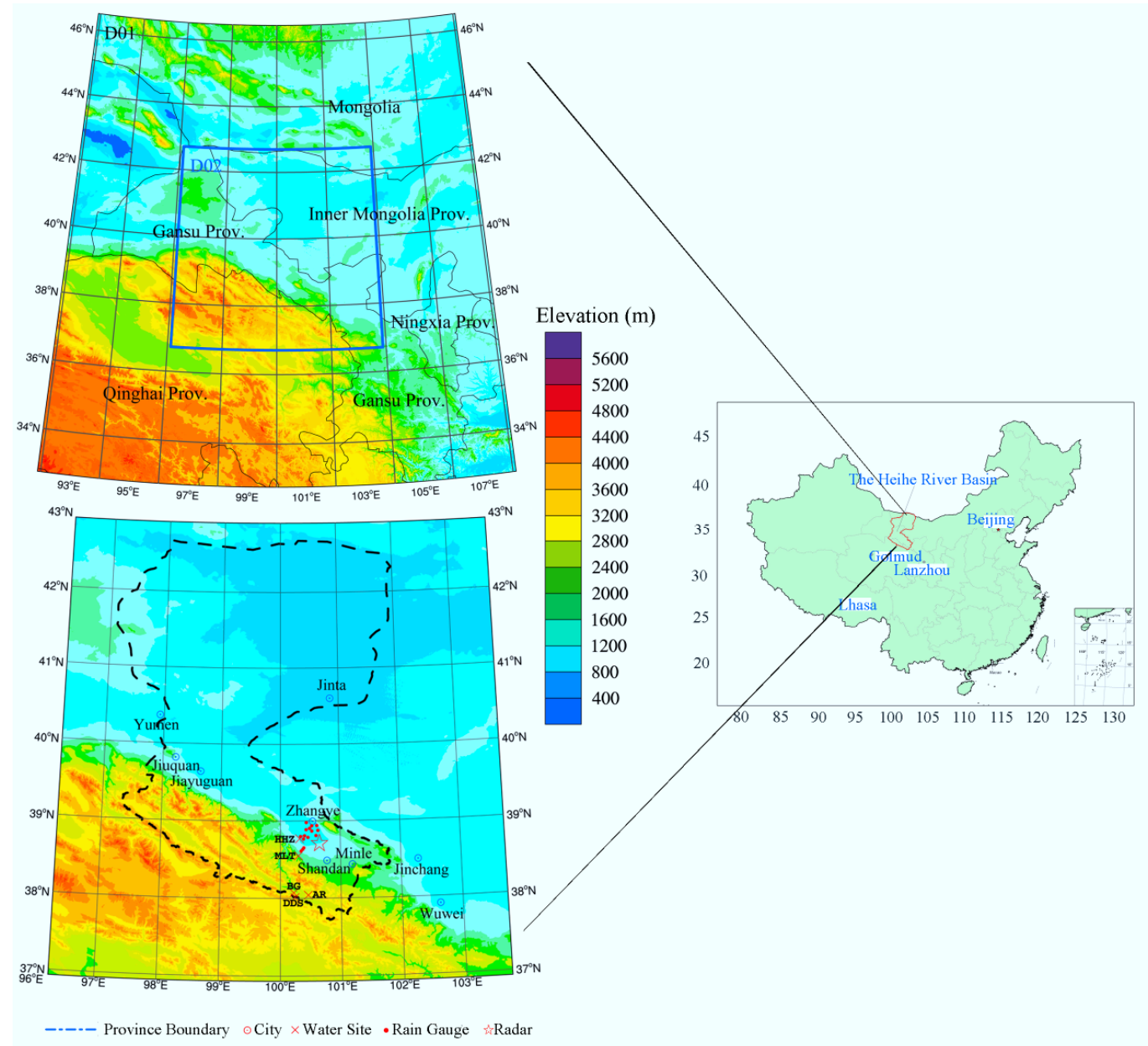

Figure 1. Two nested domains of the numerical experiment: Domain 1 consists of $60 \times 60$ grid points with a $25 \mathrm{~km}$ horizontal grid resolution, and Domain 2 consists of $130 \times 130$ grid points with a $5 \mathrm{~km}$ horizontal grid resolution.

\subsection{WRF Physical Configuration}

The Advanced Research WRF [31] (ARW) version 3.5 modeling system was used in this study. The model includes Arakawa-C grid staggering for a horizontal grid, a fully compressible system of equations, terrain-following hydrostatic pressure with vertical grid stretching, and a third-order Runge-Kutta scheme for time-split integration. The WRF physical configuration (Table 1) used in this study consisted of the WRF single-moment 5-class scheme [32] as the microphysics option, the Kain-Fritsch scheme [33] as the cumulus convection parameterization option, the Yonsei University scheme [34] as the planetary boundary layer (PBL) option, a five-layer thermal diffusion scheme as the land surface model option, and the Dudhia scheme [35] and the rapid radiative transfer model scheme [36] as the shortwave and longwave radiation options, respectively.

This study used two-way nested computational domains with $60 \times 60 \times 40$ and $130 \times 130 \times 40$ grid points and horizontal resolutions of $25 \mathrm{~km}$ and $5 \mathrm{~km}$, respectively. Two-way nesting was used to perform the model simulations (Figure 1) in a scheme where domains at different grid resolutions are run simultaneously and communicate with each other. Remote sensing rainfall assimilation was performed in the outer domain only. The coarser assimilated domain provides more precise initial and boundary conditions than that without assimilation for the finer nested domain, which feeds its calculations back to the coarser domain. 
Table 1. Physical configuration of the WRF model used in this experiment.

\begin{tabular}{ccc}
\hline Physics Processes & Domain $\mathbf{1}(\mathbf{2 5} \mathbf{~ k m})$ & Domain $\mathbf{2} \mathbf{( 5 \mathbf { ~ k m } )}$ \\
\hline Horizontal & $60 \times 60$ & $130 \times 130$ \\
Time step & $150 \mathrm{~s}$ & $30 \mathrm{~s}$ \\
Microphysics & single-moment 5-class scheme & single-moment 5-class scheme \\
Cumulus & Kain-Fritsch scheme & Kain-Fritsch scheme \\
PBL & YSU scheme & YSU scheme \\
Shortwave radiation & Dudhia scheme & Dudhia scheme \\
Longwave radiation & Rapid radiative transfer model & Rapid radiative transfer model \\
Surface-Land & 5-layer thermal diffusion & 5-layer thermal diffusion \\
\hline
\end{tabular}

\subsection{Assimilation Methodology}

In this study, 4D-Var data assimilation was used in the WRF model [31,37-39] to assimilate the remotely sensed precipitation data. Further information regarding the developmental history of WRF_DA was provided by Barker et al. [38]. The cost function equations for $4 \mathrm{D}-\mathrm{Var}$ are shown in Equations (1) and (2).

$$
\mathrm{J}=\frac{1}{2}\left[\left(\mathrm{X}_{0}-\mathrm{X}^{b}\right)^{\mathrm{T}} \mathrm{B}^{-1}\left(\mathrm{X}_{0}-\mathrm{X}^{b}\right)+\sum_{i=1}^{S}\left(H\left(\mathrm{X}_{i}\right)-\mathrm{Y}_{i}\right)^{\mathrm{T}} \mathrm{R}^{-1}\left(H\left(\mathrm{X}_{i}\right)-\mathrm{Y}_{i}\right)\right]
$$

In Equation (1), $X_{0}$ is the model state of the optimal analysis at the initial time in the time window, $i$ is the time of each observation, and $S$ is the time window (span). Here, $\mathrm{H}(\mathrm{X})$ computes the surface accumulated rainfall from atmospheric control variables (i.e., variables of $\mathrm{T}$ and $q$ ) using the WSM5 microphysical scheme:

$$
H(\mathrm{X})=\int\left(P_{\text {aut }}+P_{\text {res }}\right) d t
$$

where $P_{\text {aut }}\left(\mathrm{kg} \mathrm{kg}^{-1} \mathrm{~s}^{-1}\right)$ is the production rate of the autoconversion of cloud water to rain and $P_{\text {res }}$ $\left(\mathrm{kg} \mathrm{kg}^{-1} \mathrm{~s}^{-1}\right)$ is the production rate of the sublimation and deposition of snow/evaporation from rain.

$$
\begin{gathered}
P_{a u t}=\frac{0.104 g E_{c} \rho_{0}^{\frac{4}{3}} \cdot{ }^{\frac{7}{3}} W\left(q_{c}-q_{c 0}\right)}{\mu\left(N_{c} \rho_{w}\right)^{\frac{1}{3}}}=q_{c}=\frac{4 \pi \rho_{w} r_{c r}^{3} N_{c}}{\rho} \\
q_{c o}
\end{gathered}
$$

In Equations (3) and (4), $W$ is the Heaviside step function, $g$ is the gravitational acceleration, $E_{c}$ is the mean collection efficiency $(0.55), \mu\left(\mu=1.718 \times 10^{-5} \mathrm{~kg} \mathrm{~m}^{-1} \mathrm{~s}^{-1}\right)$ is the dynamic viscosity of air, $N_{c}$ is the concentration of cloud water droplets $\left(3 \times 10^{8} \mathrm{~m}^{-3}\right), \rho_{0}$ is the air density based on a reference state, $\rho_{w}$ is the water density, $q_{c}\left(\mathrm{~kg} \mathrm{~kg}^{-1}\right)$ is the mixing ratio of cloud water, $q_{c 0}\left(\mathrm{~kg} \mathrm{~kg}^{-1}\right)$ is the critical mixing ratio of cloud water, $r_{c r}$ is the critical mean droplet radius at which autoconversion begins, and $\rho$ is the air density.

$$
\begin{gathered}
P_{\text {res }}=\frac{4 N_{0 s}\left(S_{I}-1\right)}{\left(A_{I}+B_{I}\right)} \times\left\{\frac{0.65}{\lambda_{s}^{2}}+0.44 S_{c}^{1 / 3}\left(\frac{a_{s} \rho}{\mu}\right)^{1 / 2}\left(\frac{\rho_{0}}{\rho}\right)^{1 / 4} \times \frac{\Gamma\left[\left(b_{s}+5\right) / 2\right]}{\left.\lambda_{s}^{\left(b_{s}+5\right) / 2}\right\}}\right. \\
\lambda_{s}=\left[\frac{\pi \rho_{s} N_{0 s}}{\rho q_{s}}\right]^{1 / 4} \\
N_{0 s}\left(m^{-4}\right)=2 \times 10^{6} \exp \left[0.12\left(T_{0}-T\right)\right]
\end{gathered}
$$


In Equations (5)-(7), $N_{0 s}$ is the intercept parameter for snow, $S_{I}$ is the ice saturation, $A_{I}$ and $B_{I}$ are thermodynamic functions, $S_{c}$ is the Schmidt parameter, $\mu=1.718 \times 10^{-5}$ and is the dynamic viscosity of air, $b_{s}=0.41$ and is an exponent, $a_{s}=11.72$ and is a multiplier in the snowfall-speed formula, $\lambda_{S}$ is the slope of the snow size distribution, $T$ is temperature, $T_{0}$ is the freezing point $(273.15 \mathrm{~K}), \rho_{s}$ is the density of snow, and $q_{s}$ is the mixing ratio of snow. Additional details regarding the conversion between rain, cloud water, snow, cloud ice, and water vapor can be found in Hong et al. [32,33].

Identical frameworks were used for both WRF 4D-Var and 3D-Var, including the same observation operators, background error covariance, and minimization algorithm. The most well-known difference between $4 \mathrm{D}$-Var and 3D-Var is that $4 \mathrm{D}$-Var requires integration of the tangent linear model and adjoint model during the minimization process to achieve a dynamical balance during assimilation of the observational data in time windows. Conversely, 3D-Var uses a finite difference method to approximate the tangent linear operator when merging one-time observations during an assimilation process. Because of its low computing costs, 3D-Var can yield a much higher spatial resolution than 4D-Var [40]. However, compared to WRF 3D-Var, WRF 4D-Var has the following advantages: the ability to merge multiple observations at the time of measurement in the WRF model, the implicit definition of the flow-dependent error covariance associated with WRF forecasting, and the ability to enhance the dynamic balance of the final analysis using the WRF model as a constraint [39]. Furthermore, an automatic differentiation tool called TAPENADE [41] (Hascoët and Pascual 2004) was adopted in WRFPLUS (a necessary part of the WRF 4D-Var model) to generate a tangent linear model and an adjoint model for a given model based on its source code [42,43].

\subsection{Experimental Design}

Our real case is for assimilating 6-h accumulated precipitation. WRFDA 4D-Var is able to assimilate hourly, 3-hourly and 6-hourly precipitation data. According to experiments and related scientific papers [23], 6-h precipitation accumulations are the ideal observations to be assimilated, as this leads to better results than directly assimilating hourly data.

Three experiments were performed with and without assimilation of the remote sensing precipitation data: (1) CTL (no precipitation data assimilation in the WRF model); (2) TRMM_DA (TRMM 3B42v6 precipitation data assimilation in the WRF model); and (3) FY_DA (FY-2D precipitation data assimilation in the WRF model). In the TRMM_DA and FY_DA assimilation experiments, the assimilation time window spanned from 00:00 UTC to 06:00 UTC on 21 June 2008. The rainfall observation file containing rainfall data accumulated during the assimilation time window was assimilated at 06:00 UTC using the WRF 4D-Var assimilation system.

In the CTL experiment, the conventional WRF model simulation was performed without observed data assimilation. The TRMM_DA experiment included the TRMM remote sensing precipitation product, which was assimilated from 00:00 UTC to 06:00 UTC on 21 June using the WRF 4D-Var method. The FY_DA experiment was similar to the TRMM_DA, except the FY-2D remote sensing precipitation product was used for assimilation rather than the TRMM product. In all the experiments, the model was integrated for $48 \mathrm{~h}$ from 00:00 UTC on 21 June to 00:00 UTC on 23 June 2008.

\subsection{Characteristic of the Background Error Covariance}

Background error covariance is an important component of a data assimilation system and plays a critical role in successful assimilation by determining the information distribution of data in space and between variables, describing the weights of the observations and background fields in an analysis, controlling the spread of the observed information from the observation position to its surroundings, and ensuring that the model variables remain dynamically coordinated [44-46]. Since the release of WRF_DA version 3.1, the NMC method has been provided to users to define the domain-dependent background error covariance, including CV5, CV6, and CV7. The main differences between CV5, CV6, and CV7 are described in "Running gen_be" in Chapter 6: WRF Data Assimilation in the ARW version 3 modeling system user's guide (v3.7, July 2015). In this study, values of the background error 
covariance were generated using the NMC-CV5 (local statistical method in WRF) method [47] with a $(\mathrm{T}+24)$ minus $(\mathrm{T}+12)$ forecasting difference. The input data used to statistically generate background errors were WRF forecasts from 21 May 2008, to 21 June 2008. Figure 2 shows the first five feature vectors of the control variables, including the stream function, velocity potential, horizontal wind component in the $x$-direction, and relative humidity resulting from the vertical autocovariance matrix based on recursive filters. The background error length scaling parameter was 0.5 , and the background error variance was 0.5 for all variables.
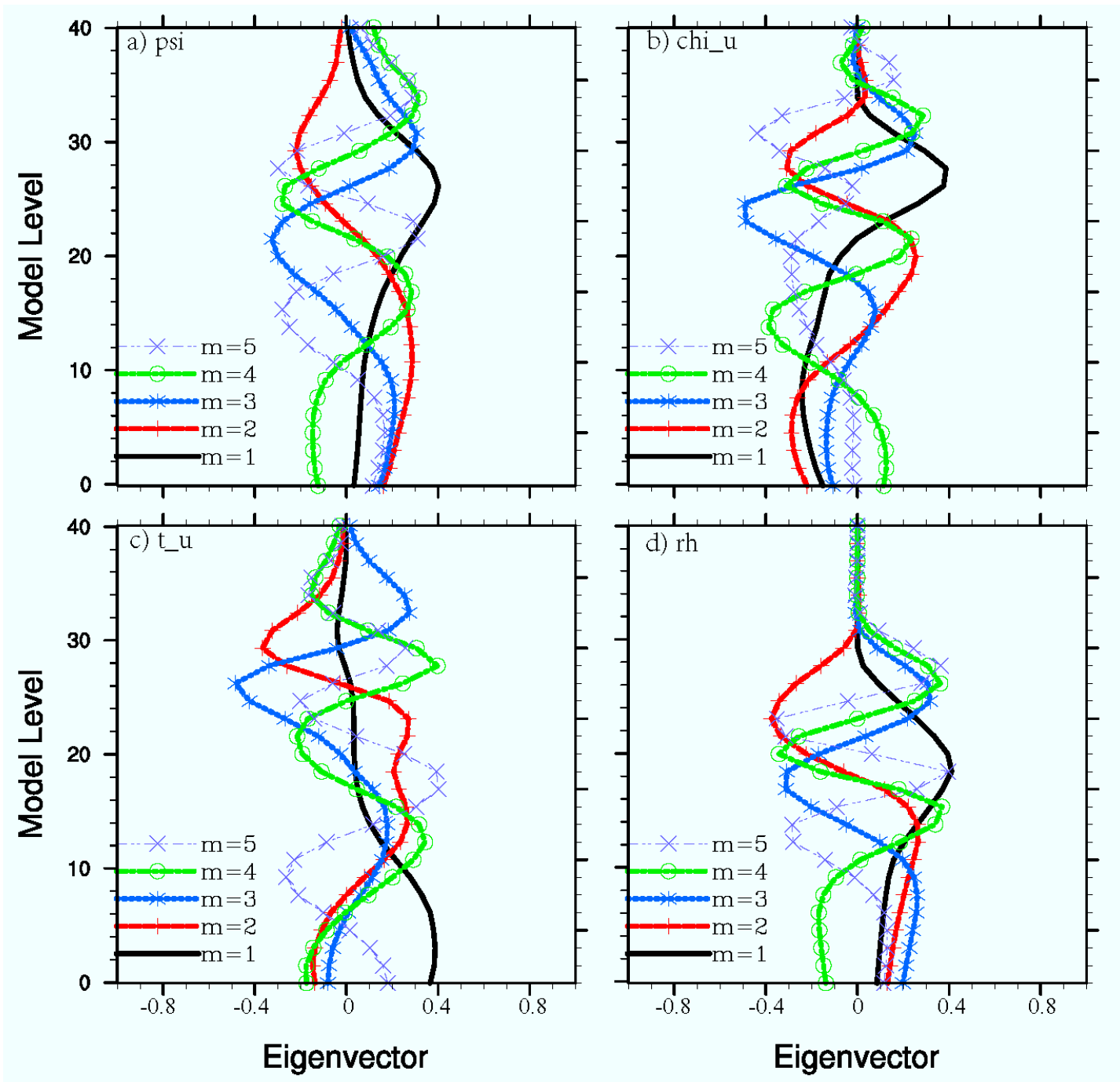

Figure 2. Five eigenvectors of control variables: a) stream function; b) unbalanced part of velocity potential; c) unbalanced part of temperature; d) relative humidity. 


\subsection{Remote Sensing Precipitation Products}

\subsubsection{TRMM}

TRMM was launched in November 1997 [48]. The rainfall measuring instruments on the TRMM satellite include precipitation radar (PR; an electronic scanning radar system operated at $13.8 \mathrm{GHz}$ ), the TRMM microwave imager (TMI; a nine-channel passive microwave radiometer), and a visible and infrared scanner (VIRS; a five-channel visible/infrared radiometer). TRMM 3B42 [49] consists of multisatellite (TRMM, AMSR, SSM/I, AMSU, Geo-IP) precipitation data calibrated based on TRMM PR/TMI (combined). TRMM 3B42 has the goal of producing TRMM-merged high-quality infrared precipitation and root-mean-square precipitation error estimates at a $0.25^{\circ} \times 0.25^{\circ}$, every $3 \mathrm{~h}$ resolution and covering $50^{\circ} \mathrm{N}-50^{\circ} \mathrm{S}, 0^{\circ} \mathrm{W}-180^{\circ} \mathrm{W}$, and $0^{\circ} \mathrm{E}-180^{\circ} \mathrm{E}$.

\subsubsection{FY-2D}

The Chinese meteorological Fengyun (FY) satellites are operated by the National Satellite Meteorological Center (NSMC) of the China Meteorological Administration (CMA) (CMA 2009) and were launched in series. The series include Fengyun-1 (FY-1), Fengyun-2 (FY-2), and Fengyun-3 (FY-3). The odd and even numbered series are polar-orbiting and geostationary satellites, respectively. FY-2 series satellites are the first-generation of geosynchronous (GEO) Earth observation satellites. FY-2D is the fourth flight unit of the FY-2 series and was launched on 8 December 2006. The measuring instruments on the FY-2D satellite include five channel sensors, one visible channel with a $1.25 \mathrm{~km}$ resolution and four infrared channels with a $5 \mathrm{~km}$ resolution, on stretched visible and infrared spin scan radiometers that track clouds and water vapor features. The FY-2D precipitation products were developed based on a lookup table method and can be used to analyze the relationship between precipitation, cloud classification, and cloud development [50] at a $5 \mathrm{~km} \times 5 \mathrm{~km}, 15$-min resolution covering $0^{\circ} \mathrm{N}-50^{\circ} \mathrm{N}$ and $55^{\circ} \mathrm{E}-155^{\circ} \mathrm{E}$. The products were upscaled to match the 1 st domain resolution at $0.25^{\circ}$. The FY-2D precipitation errors were calculated based on the CMA and the WATER observational data using the residual Kriging interpolation algorithm.

\subsubsection{Remote Sensing Data Preprocessing}

Both TRMM 3B42 precipitation and FY-2D precipitation products are stored in hierarchical data format, the former with a latitude-longitude geographical projection and the latter with a geostationary satellite normalized projection. A Fortran program was written to convert observational data in a hierarchical format to the standard format used in WRFDA. Data from both precipitation products are given in text format and include the following fields: PLATFORM, DATE, LEVELS, LATITUDE, LONGITUDE, ELEVATION, ID., HEIGHT, RAINFALL DATA, QC, and ERROR. Among these fields, HEIGHT and QC are assigned "missing values", and ERROR in the TRMM product is based on the TRMM 3B42 precipitation product.

\subsubsection{Comparison between the TRMM and FY-2D Remote Sensing Precipitation Products}

Figure 3 shows the spatial distributions of the TRMM and FY-2D remote sensing precipitation products accumulated between 00:00 UTC and 06:00 UTC on 21 June 2008. The two groups of remote sensing precipitation data were interpolated from their original projections to the Lambert projection, which was used in the WRF model in the present study, to compare data from these two groups in one standard framework. The distributions of these two types of satellite precipitation are slightly different, although they have common characteristics. Notably, the accumulated precipitation in the southern part of the study area is larger than that in the northern part. This observation suggests that the rain vapor moves from the southern part to the northern part of the study area, especially over the upstream portion of the HRB. 


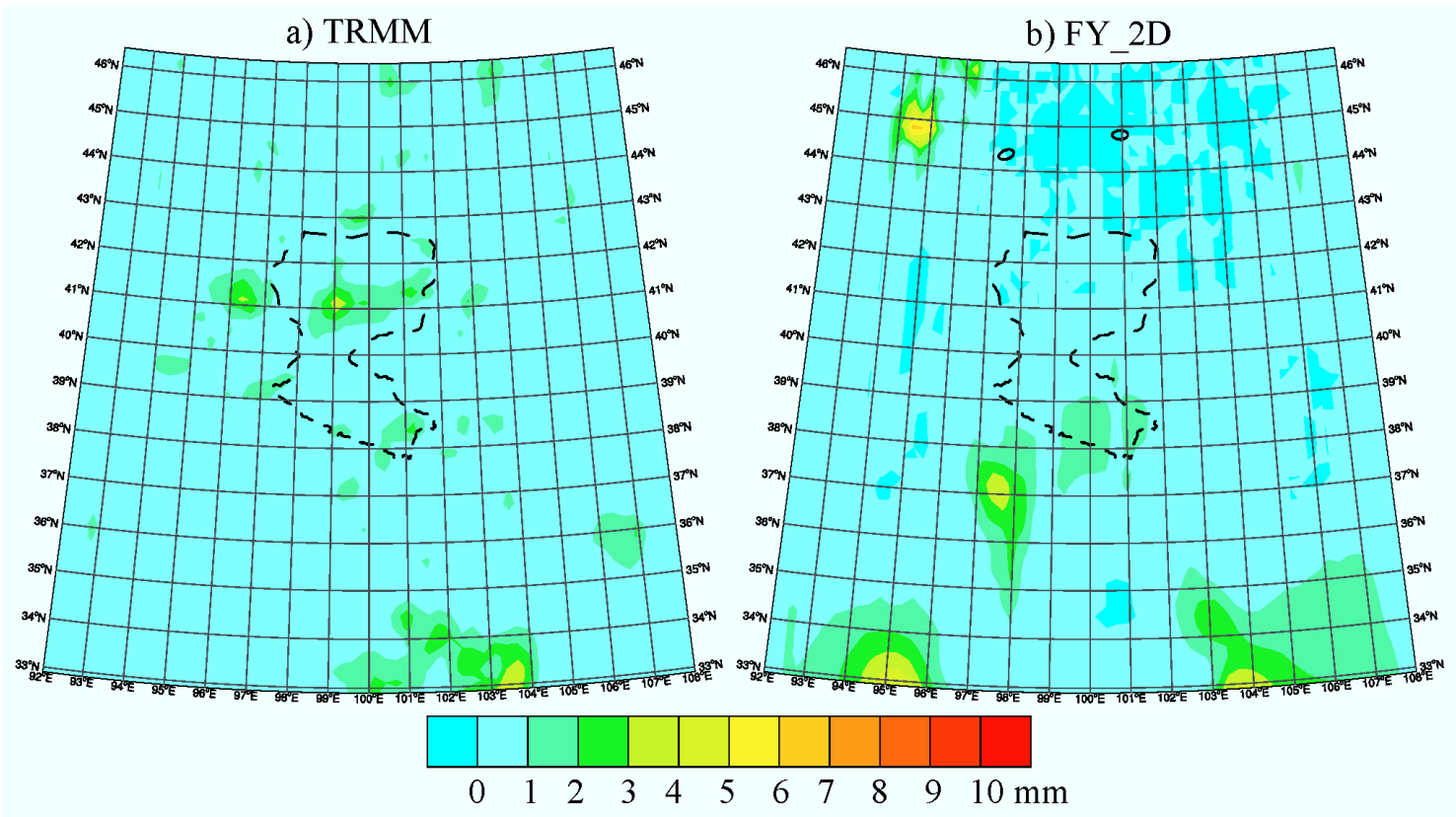

Figure 3. Spatial distributions of accumulated remote sensing precipitation from 00:00 UTC to 06:00 UTC on 21 June 2008, over the first domain: (a) TRMM 3b42 V6 precipitation product; (b) FY-2D precipitation product.

\section{Results}

\subsection{Single Observation Test}

The single observation test enables researchers to understand how the background and observational error statistics work in a framework within which the data assimilation system is linked to a specific model. Single observation tests must be performed before the real data experiments. In the current single observation test, num_pseudo was set to 1 for each control variable at the grid point $(9,30,30)$, which is the location relative to the total $(40,60,60)$. The first dimension is the vertical model layer $(9 / 40)$, the second dimension is latitude $(30 / 60)$, and the last dimension is longitude $(30 / 60)$. This test (Figure 4) shows that the statistical covariance of background and observational error can be applied in the real case of a WRF 4D-Var analysis.

\subsection{Observation Correlation Analysis in the First Domain}

Because the satellite precipitation data have been assimilated into the first domain in the WRF model, the initial and boundary conditions of the second domain are provided by the first domain. Using this criterion, we calculated the correlations derived from the satellite precipitation data and the assimilation results within the first domain along the vertical layer, which are shown in Figure 5. 


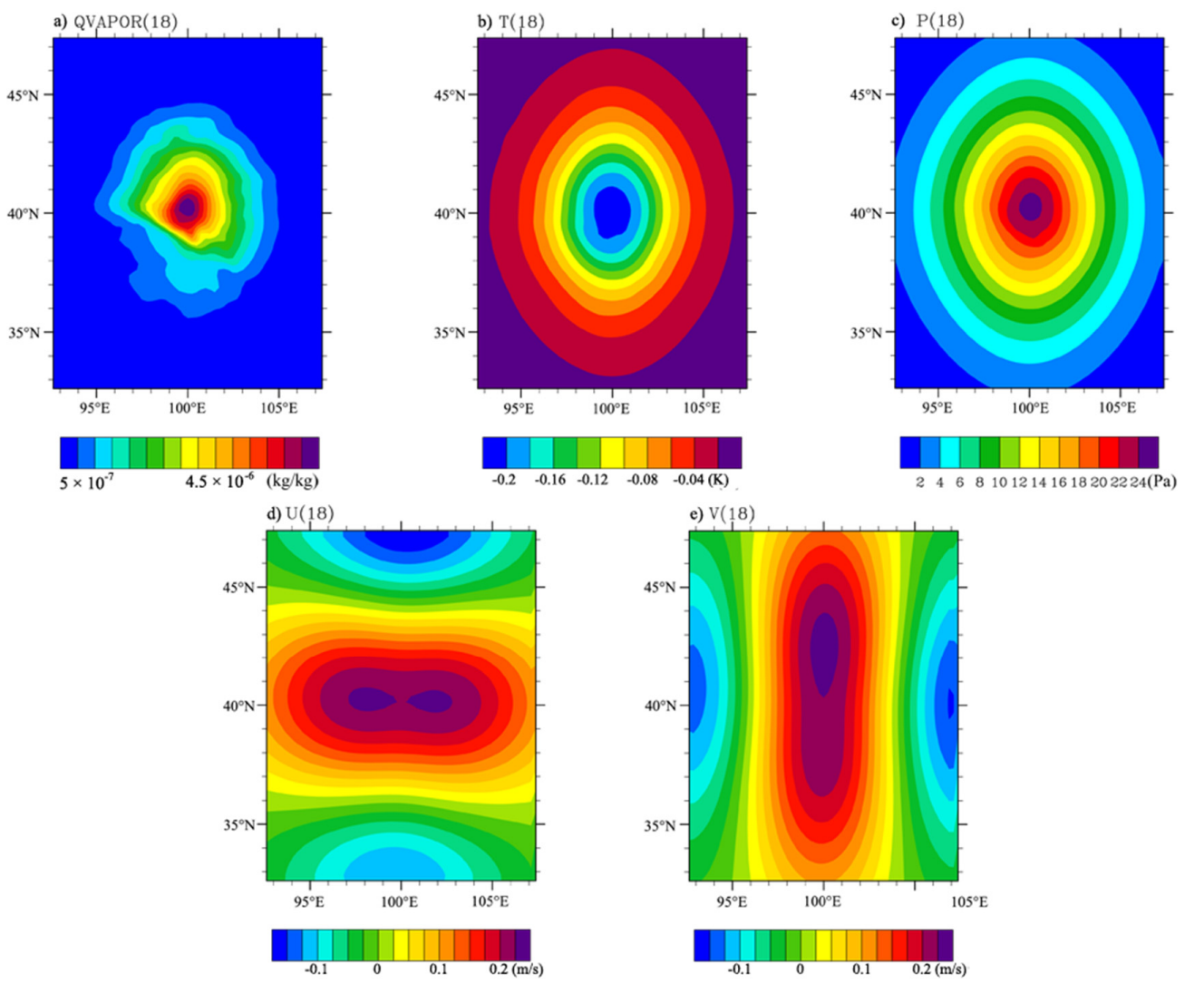

Figure 4. Assimilation tests of single observations of control variables at a central point: (a) vapor observations; (b) temperature observations; (c) pressure observations; (d) U observations; and (e) V observations.
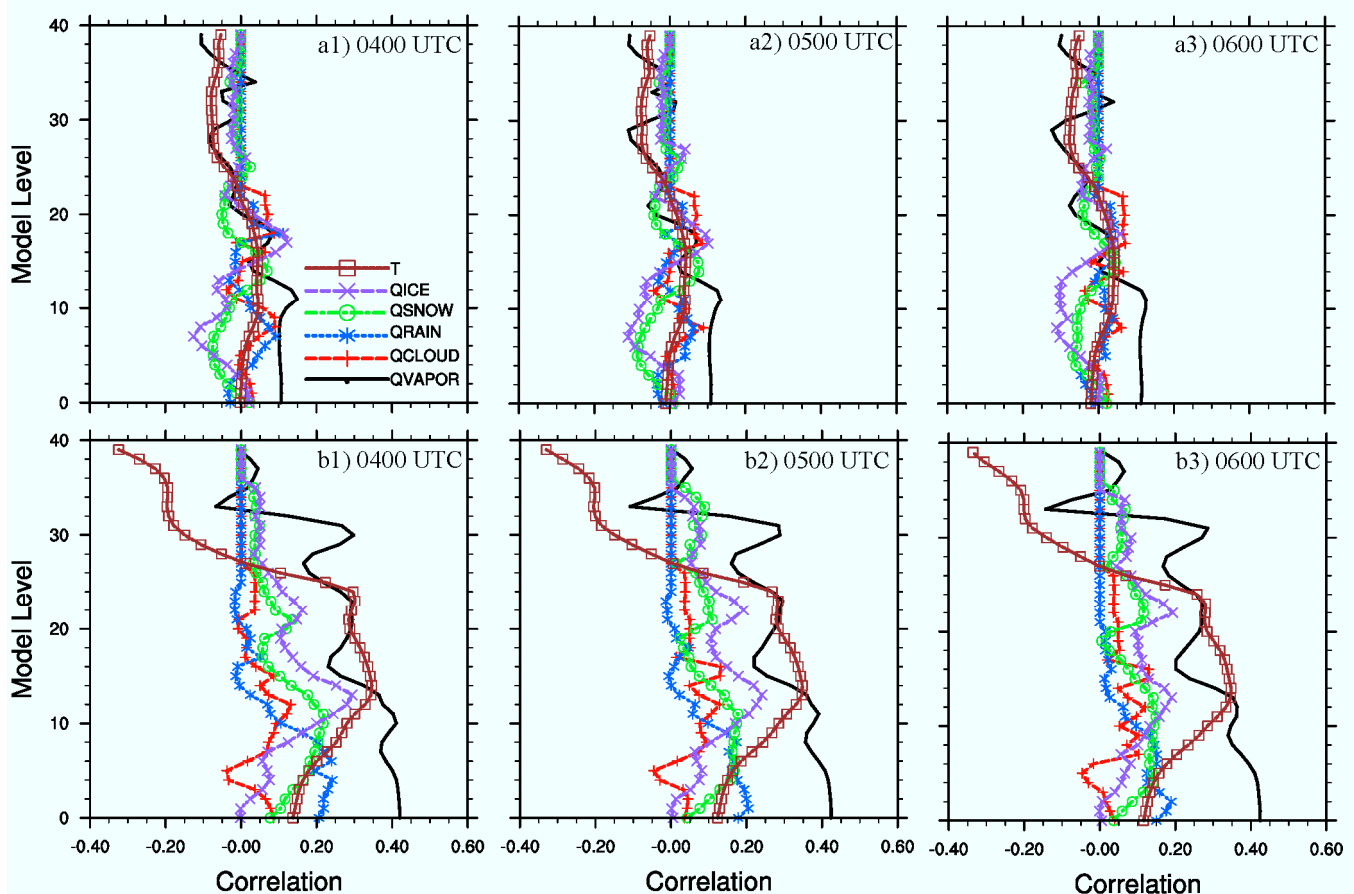

Figure 5. Correlations between remote sensing precipitation products and hydrometeorological variables or temperature from 04:00 UTC to 06:00 UTC on 21 June 2008: (a1-a3) from 04:00 to 06:00 for TRMM assimilation; (b1-b3) from 04:00 to 06:00 for FY assimilation. 
Figure 5 shows the correlation profiles between the remote sensing precipitation products and simulated hydrometeorological variables, or temperature from 04:00 UTC to 06:00 UTC on 21 June 2008. The variability in the correlations between the FY-2D precipitation and hydrometeorological variables or temperature is greater than that associated with the correlations between the TRMM precipitation and hydrometeorological variables or temperature. The correlations between temperature and the satellite precipitation products are negative in the upper vertical layers but positive in the lower vertical layers (especially in the middle and upper troposphere). These correlations then gradually decrease in the lower troposphere. The absolute values of the correlations between FY-2D and temperature are far greater than those between TRMM and temperature. The correlation profiles between the satellite precipitation products and VAPOR are mostly positive, suggesting that higher precipitation corresponds to higher hydrometeorological mixing ratios. Additionally, the correlation between FY-2D and VAPOR is far higher than that between TRMM and VAPOR. The correlation profiles between the TRMM precipitation product and QRAIN (blue lines) or QCLOUD (red lines) are positive. The correlation profiles between the TRMM precipitation product and QSNOW (green lines) and QICE (purple lines) are negative. The correlation profiles between the FY-2D precipitation product and the hydrometeorological variables are mostly positive.

As time advances from 10:00 UTC to 24:00 UTC on 21 June 2008, the correlation profiles between the TRMM precipitation product and temperature increase, while those between the TRMM precipitation product and VAPOR decrease. Additionally, the correlation between the FY-2D precipitation product and VAPOR decreases.

\subsection{Control Variable Simulation in the Second Domain}

The spatial distributions of the temperature forecasting difference and water vapor mixing ratio forecasting difference over $6 \mathrm{~h}, 12 \mathrm{~h}, 24 \mathrm{~h}$, and $48 \mathrm{~h}$ at the ninth layer (out of 40 layers) between the assimilation and control experiments are shown in Figures 6 and 7 , respectively. A strong negative temperature difference is obvious in the middle stream of the HRB after $12 \mathrm{~h}$ forecasting in both assimilations. A much stronger negative temperature difference can be observed over the whole region after $48 \mathrm{~h}$, especially in the southern part of the Qilian Mountains, midstream areas, and downstream areas. The temperature difference between the FY-DA and CTL experiments is much larger than that between the TRMM-DA and CTL experiments. The mixing ratio increases over the entire HRB region, especially based on the $24 \mathrm{~h}$ and $48 \mathrm{~h}$ forecasting. An evident positive difference in the water vapor mixing ratio between the DA and CTL experiments can be observed after $24 \mathrm{~h}$ and $48 \mathrm{~h}$ in the upstream and midstream areas, but this observation is not evident in downstream areas.

\subsection{Precipitation Foresting over $12 h, 24 h$ and $48 h$}

Figure 8 shows the accumulated precipitation at $12 \mathrm{~h}, 24 \mathrm{~h}$, and $48 \mathrm{~h}$ based on TRMM, FY, and other precipitation data obtained via a control simulation, TRMM assimilation, and FY assimilation. Compared with the WRF simulation without assimilation, after $24 \mathrm{~h}$ of simulation, the accumulated precipitation forecasts with assimilated remote sensing precipitation products were slightly higher than those of the control model (no assimilation) for the southeastern part of the upper HRB. After $48 \mathrm{~h}$ of simulation, the accumulated precipitation forecasts with assimilated remote sensing precipitation products were considerably higher than those of the control model (no assimilation) for the southeastern upper HRB, especially the forecast based on the assimilation of the FY-2D precipitation product. 

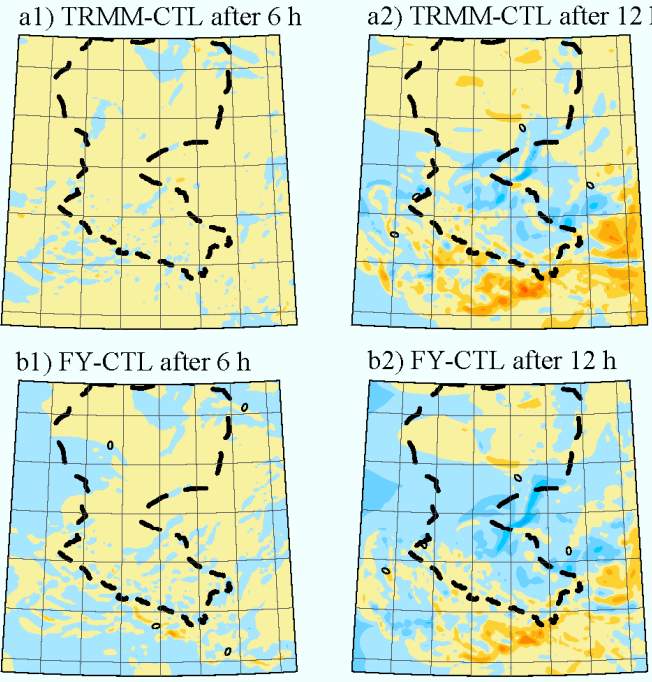

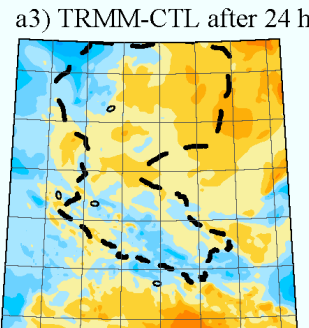

b3) FY-CTL after $24 \mathrm{~h}$

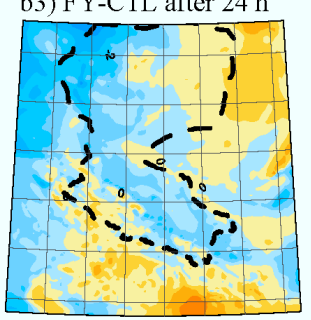

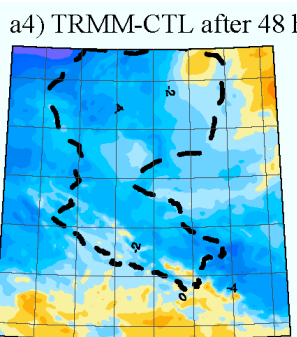

b4) FY-CTL after $48 \mathrm{~h}$

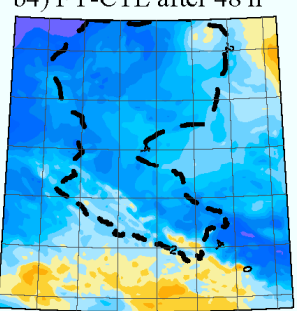

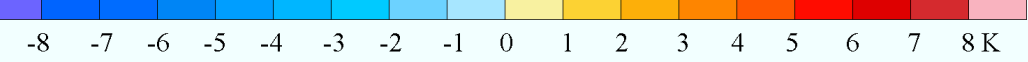

Figure 6. Spatial distribution of temperature (K) forecasting difference in the ninth model layer at 6 h, 12 h, 24 h, and 48 h: (a1-a4) for TRMM assimilation minus control simulation; (b1-b4) for FY assimilation minus control simulation.
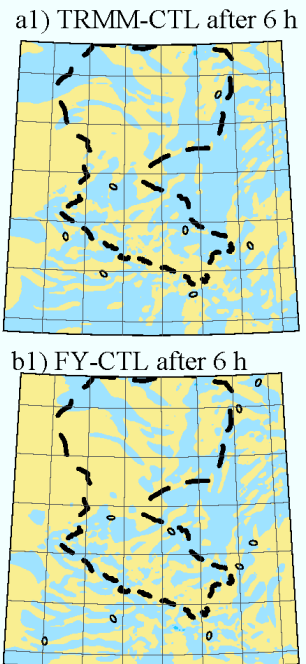
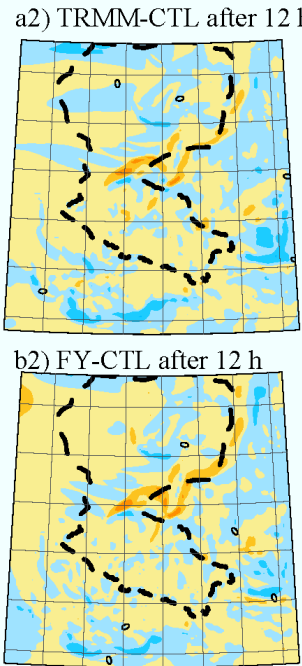

a3) TRMM-CTL after $24 \mathrm{~h}$
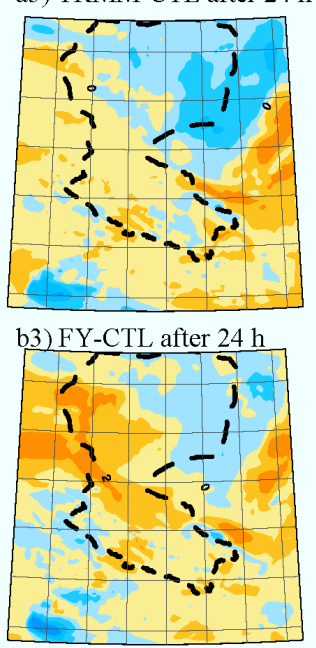

a4) TRMM-CTL after $48 \mathrm{~h}$
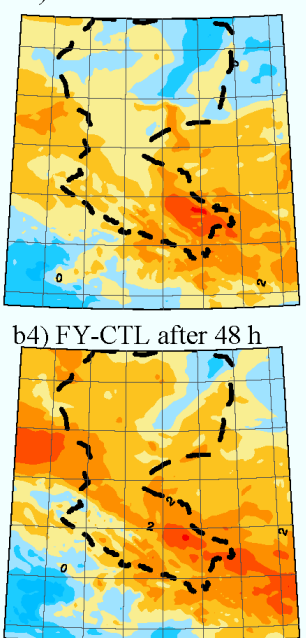

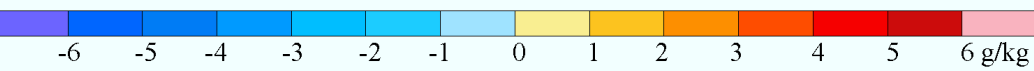

Figure 7. Spatial distribution of water vapor mixing ratio $(\mathrm{g} / \mathrm{kg})$ forecasting difference in the ninth model layer at $6 \mathrm{~h}, 12 \mathrm{~h}, 24 \mathrm{~h}$, and $48 \mathrm{~h}$ : (a1-a4) for TRMM assimilation minus control simulation; (b1-b4) for FY assimilation minus control simulation. 

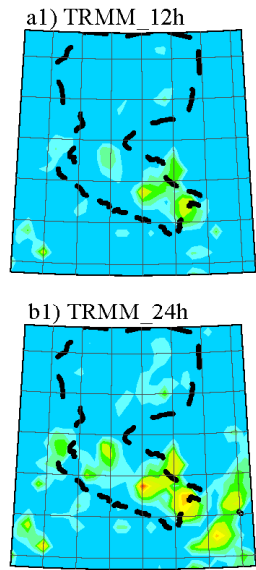

c1) TRMM $48 \mathrm{~h}$

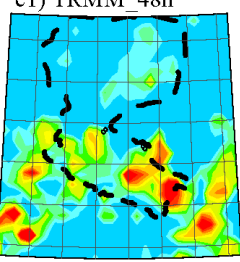

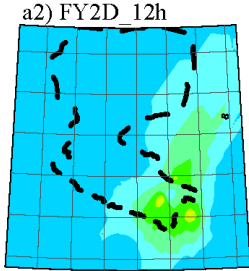

b2) FY2D 24h

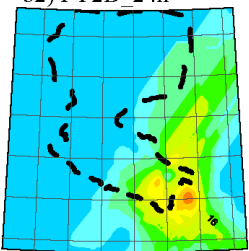

c2) FY2D_48h

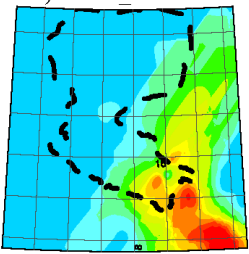

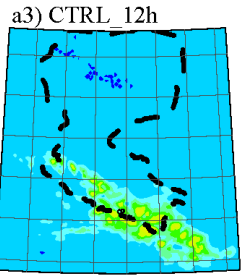

b3) CTRL 24h

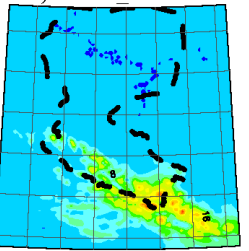

c3) CTRL_48h

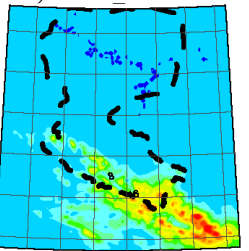

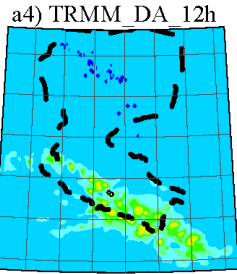

b4) TRMM DA 24h

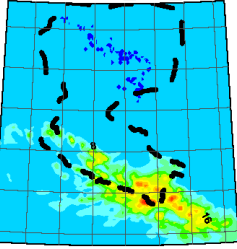

c4) TRMM DA 48h

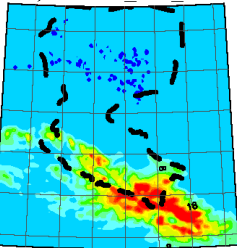

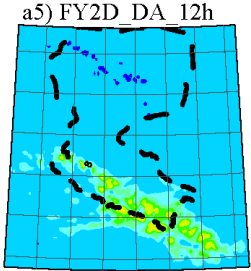

b5) FY2D DA 24h

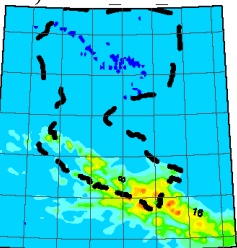

c5) FY2D DA 48h

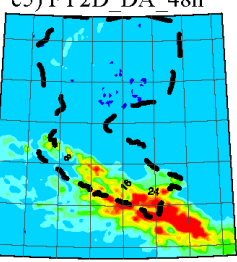

+

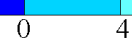

$\begin{array}{lll}4 & 8 & 12\end{array}$

28

Figure 8. Accumulated precipitation at $12 \mathrm{~h}, 24 \mathrm{~h}$, and $48 \mathrm{~h}$ from 21 to 23 June 2008 (the assimilation window is from 00:00 UTC to 06:00 UTC, 21 June 2008): (a1)/(b1)/(c1) for TRMM 3B42 V6 remote sensing products; (a2)/(b2)/(c2) for FY-2D remote sensing products; 3) (a3)/(b3)/(c3) for control simulation; (a4)/(b4)/(c4) for TRMM assimilation; (a5)/(b5)/(c5) for FY assimilation.

\subsection{Evaluation of Precipitation Forecasting Using Rain Gauge Data}

Figure 9 shows the accumulated precipitation curves for the period from 00:00 UTC to 15:00 UTC on 21 June 2008. The figure compares rainfall observations, the control simulation, the TRMM assimilation, and the FY assimilation at nine rain gauges. The accumulated precipitation simulated by the control experiment (black lines) was far less than what was observed (red lines). The accumulated precipitation forecast of WRF 4D-Var with assimilated TRMM and FY remote sensing precipitation products agreed well with the observed data. At most gauges, the accumulated precipitation volumes simulated by assimilating the FY products (blue) were much greater than those simulated by assimilating TRMM (green). At gauges N01, N02, N05, N07, and N09, the accumulated precipitation values simulated by assimilating the FY products were greater than the observed values, but the observations were greater than the observed values, however, the observations were greater than the values simulated by assimilating the TRMM products. This result suggests that the assimilation of remote sensing precipitation products into a WRF model using $4 \mathrm{D}$-Var can improve the initial and boundary conditions of the model [51]. 

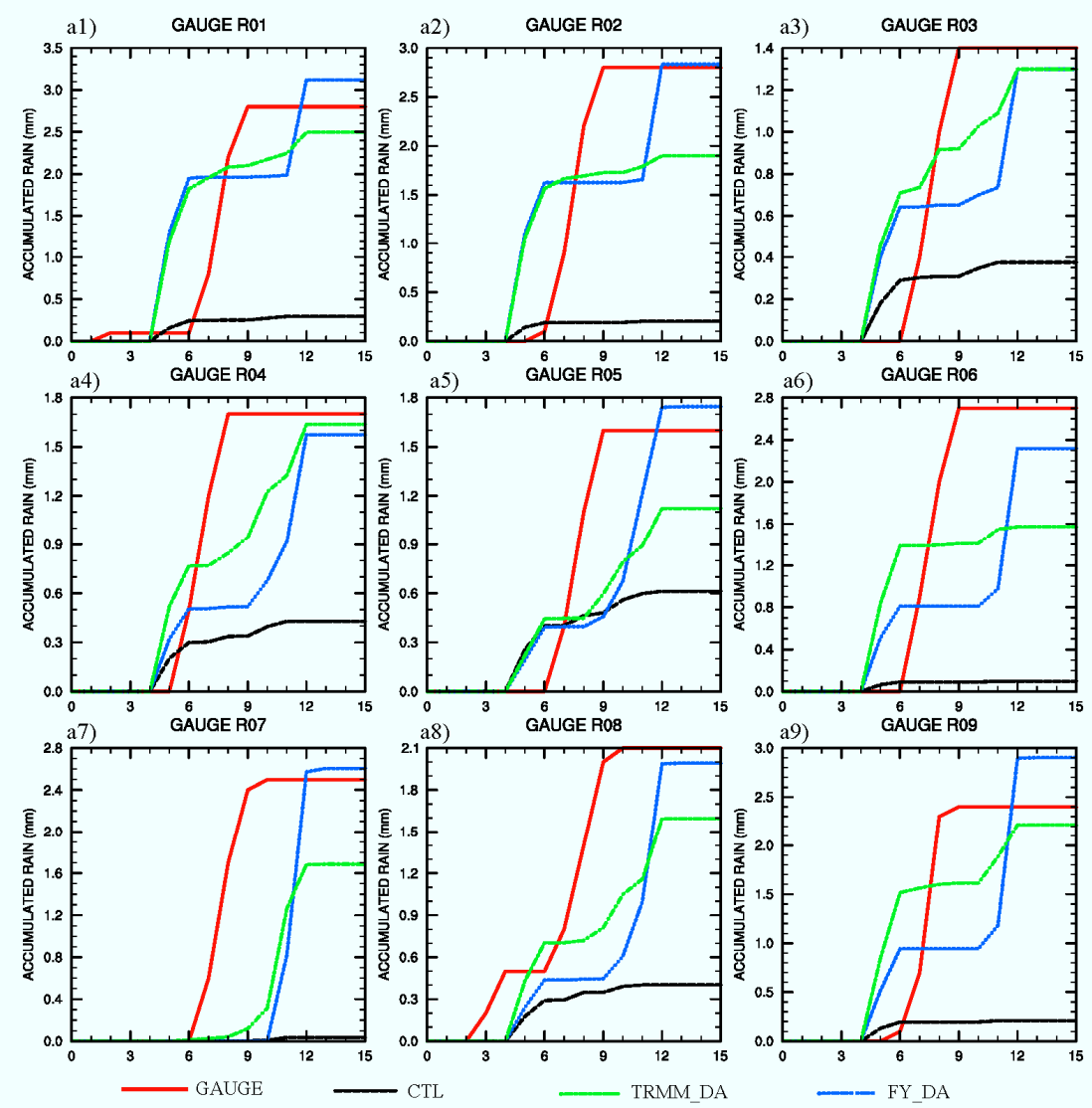

Figure 9. Comparisons of accumulated rainfall curves for the control simulation, TRMM assimilation, FY assimilation, and gauge observations (from 00:00 UTC to 15:00 UTC on 21 June 2008): (a1-a9) from Gauge R01 to Gauge R09.

Figure 9 shows that the accumulated precipitation simulated by the control experiment was far less than that simulated by assimilating the remote sensing precipitation products into the WRF model using the $4 \mathrm{D}$-Var method. A potential reason for this result is that initialization took longer in the control experiment than in the data assimilation experiments. A certain initialization time is required in NWP models to develop accurate mesoscale and large-scale circulations. The initialization time can be reduced by using data assimilation to steer the model toward the observed state, and a data assimilation cycle can shorten the initialization time by ensuring that the modeled values of the water vapor mixing ratio are close to the actual values.

Figure 10 shows the $6 \mathrm{~h}$ accumulated precipitation root mean squared error at the between guage observation and control experiment, precipitation assimilating experiments including TRMM and FY, at the second domain. The RMSEs of FY and TRMM assimilation are much smaller than that of control experiment. 


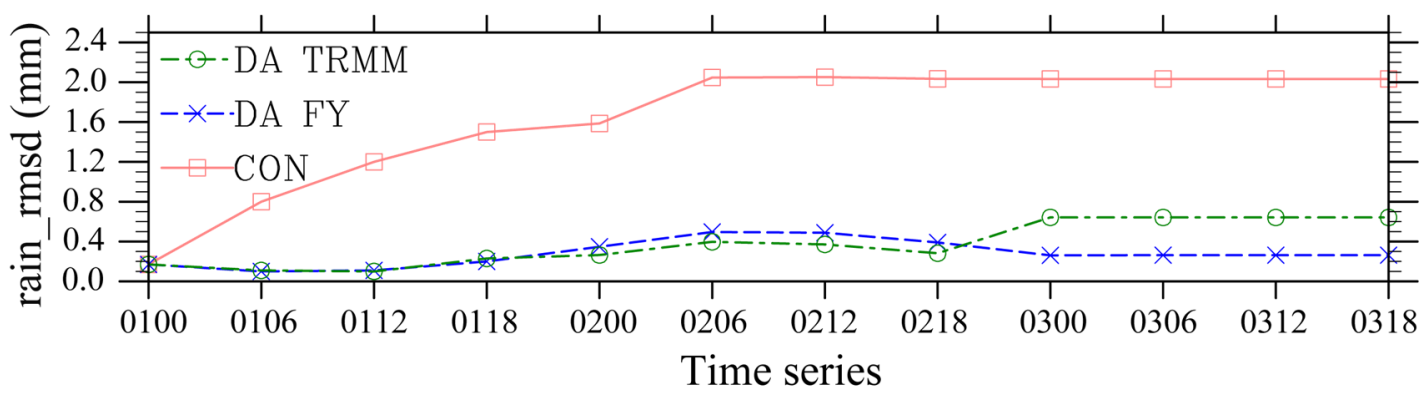

Figure 10. Six-hour accumulated precipitation root mean squared error between precipitation simulation and gauge observations from 21 June to 24 June 2008.

\subsection{Evaluation of Other Variables Using Observation Data}

In addition to the improvement achieved in estimating hydrometeorological variables by assimilating remote sensing precipitation products, the effect of this assimilation on other meteorological land surface variables was assessed using a Taylor diagram (Figure 11) for hourly observation stations based on the WATER projection (shown in Figure 1 as red dots). These variables included pressure (PSFC), temperature (T2), relative humidity (RH2), wind speed (WS10), longwave downward radiation (GLW), and shortwave downward radiation (SWDOWN).

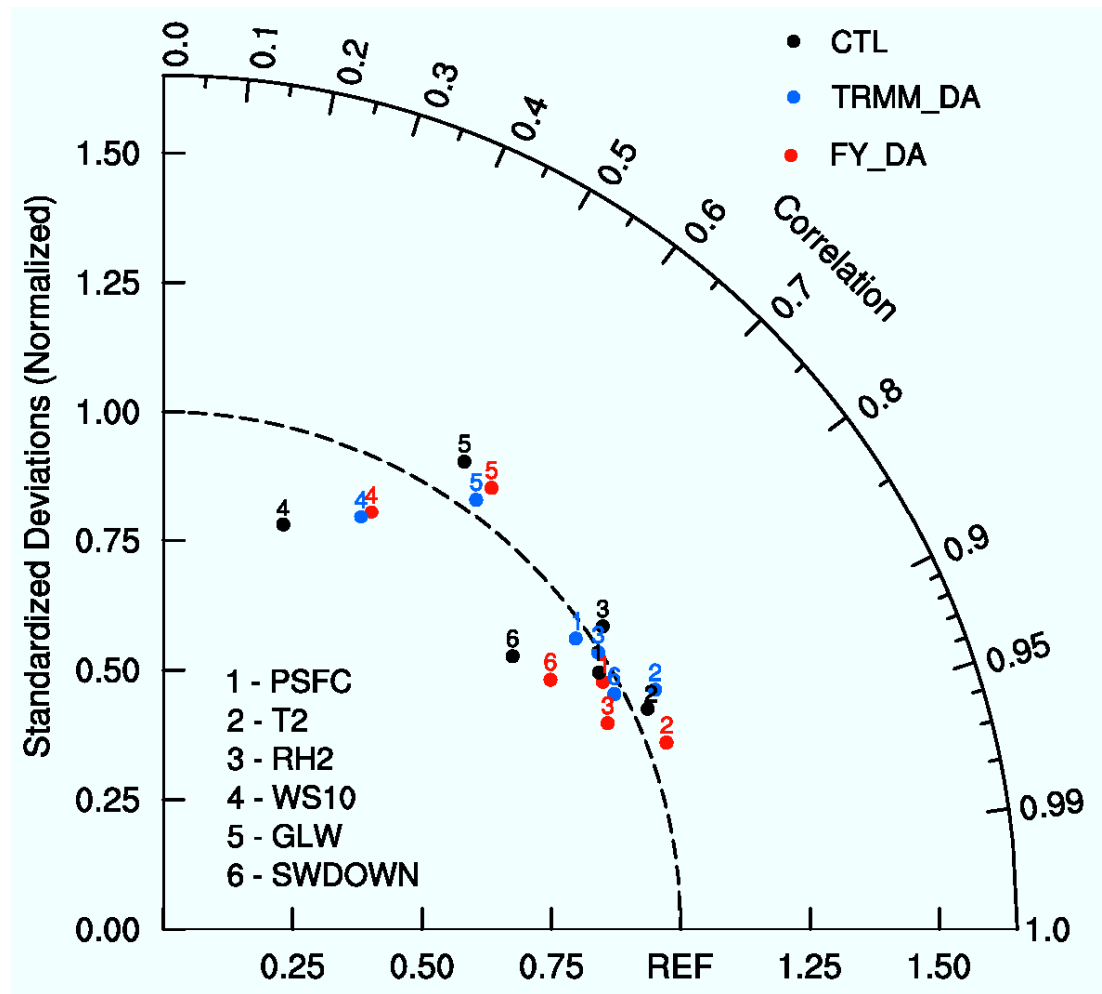

Figure 11. Taylor diagram of other atmospheric variables.

Figure 11 shows that the pressures and temperatures produced by the CTL and DA simulations match well with those observed. The simulated wind speed and longwave downward radiation have much lower cross-correlation coefficients than did other atmospheric variables. The improvements in relative humidity (No. 3 in Figure 11), wind speed (No. 4 in Figure 11), and shortwave downward radiation (No. 6 in Figure 11) are notable. Temperature and relative humidity simulated by FY 4DVar is better than those by TRMM 4 DVar or control simulation. The radiation including downward 
longwave and shortwave simulated by TRMM 4DVar is much better than those by FY 4DVar or control simulation.

\subsection{One More Case Study on 1 July 2015}

This case study assimilates TRMM 3B42, Global Precipitation Measurement dataset (GPM), and FY-2G precipitation dataset (accumulated rainfall between 00:00 UTC and 06:00 UTC) on 1 July 2015. The model is integrated for $72 \mathrm{~h}$ starting from 00:00 UTC from 1 July to 4 July 2015. Here, FY-2D has been suspended since 30 June 2015, so FY-2G precipitation products takes place of FY-2D in this case study. GPM was launched on 27 February 2014, carrying an advanced radar/radiometer system to measure precipitation from space [52], here the near-real time product in the IMERG suite of products that currently runs about $6 \mathrm{~h}$ after observation time named the Integrated Multi-satellitE Retrievals for GPM (IMERG) Early Run product was used to do GPM assimilation experiment. The validation data is collected at HiWATER super stations [29].

Same as the first case study, Figures 12-14 show the comparisons of daily precipitation spatial distribution, accumulated rainfall curves and $6 \mathrm{~h}$ accumulated precipitation root mean squared error between control experiment and precipitation assimilating experiments including TRMM, FY and GPM. The accumulated precipitation simulated by control experiment is far less than those by assimilating experiments. The RMSEs of assimilating experiments are, much smaller than that of control experiment.
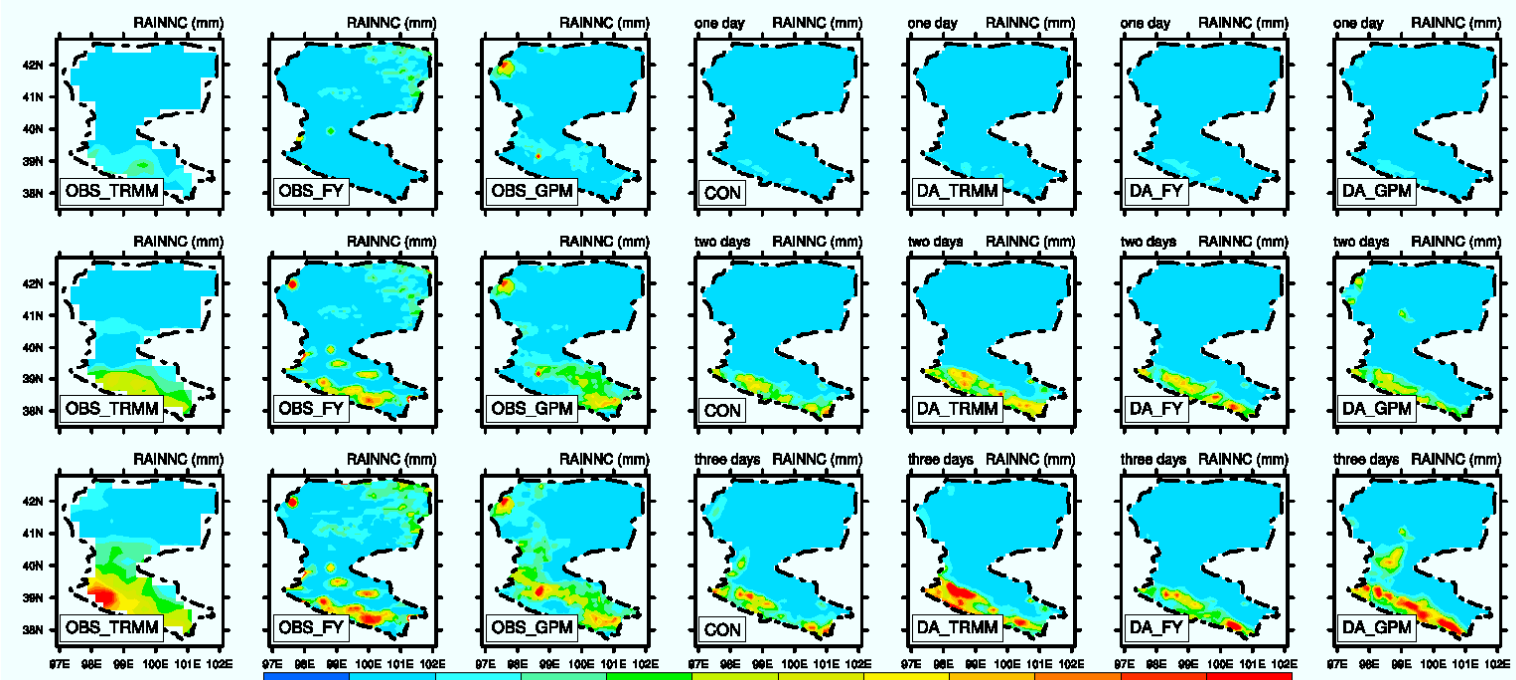

0

30
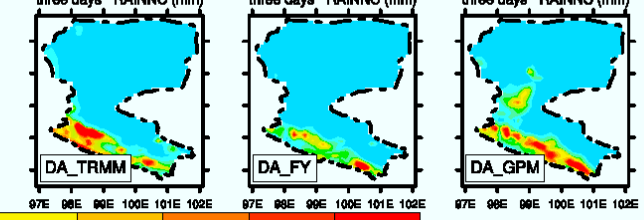

Figure 12. Accumulated precipitation at $24 \mathrm{~h}, 48 \mathrm{~h}$, and $72 \mathrm{~h}$ from 1 July to 3 July 2015 (the assimilation window is from 00:00 UTC to 06:00 UTC, 1 July 2015). 

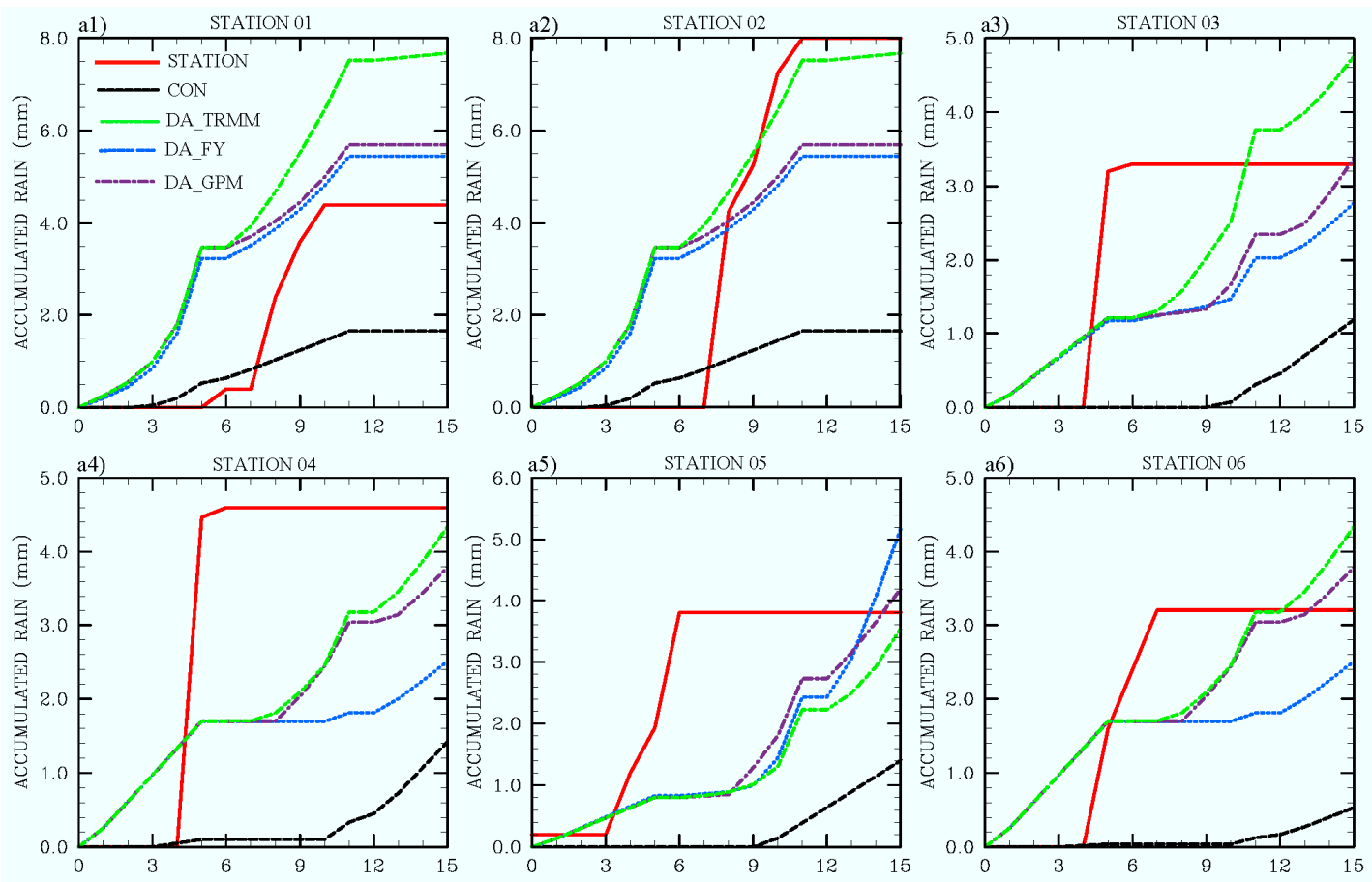

Figure 13. Comparisons of accumulated rainfall curves for the control simulation, TRMM assimilation, FY assimilation, and HiWATER super stations (from 00:00 UTC to 15:00 UTC on 1 July 2015): (a1-a6) from station 01 to station 06 .

From July 1 to July 3, 2015

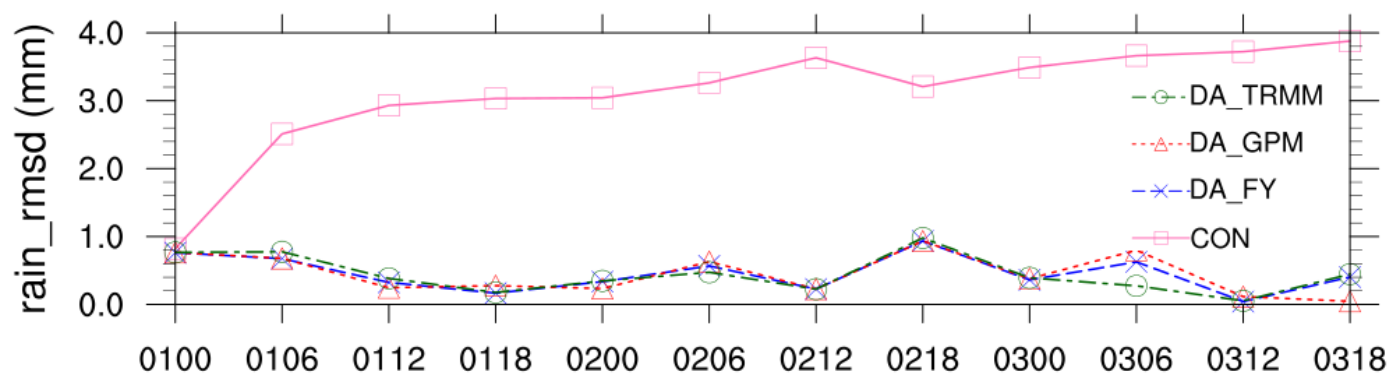

Time series

Figure 14. Six-hour accumulated precipitation root mean squared error between precipitation simulation and HiWATER station observation from 1 July to 4 July 2015 at the second domain.

\section{Discussion}

\subsection{Comparing Precipitation Products between Satellite-retrieved and NWPs' Simulation}

Compared with the precipitation yielded by the WRF simulation, satellite-retrieved precipitation products cannot describe the watershed scale in detail, erasing the heterogeneity caused by the diverse landscape and complex terrain of the inland river basin. The reasons for this deficiency are as follows: (1) the spatial resolution is too coarse to express the complex terrain effect on precipitation; and (2) no interaction mechanism between the atmosphere and the land surface during precipitation retrieval process. The WRF model coupled with the land surface model can embody the interaction between a complex land surface and the atmosphere and then reflect the effect of the local complex terrain on precipitation, especially over the upstream area. However, the quality of precipitation simulated 
by WRF model should be further improved by assimilating the remote sensing precipitation data presented in this paper.

\subsection{Effect of Remote Sensing Product Assimilation on WRF Forecasting}

Temperature and water vapor were considered as two key elements when evaluating the data assimilation results of this study. The probability of precipitation increases if there is sufficient moisture in the air and a forcing mechanism, such as a cold front, is approaching the area. A cold front is helpful in cooling rising warm air, condensing moisture, and forming clouds and precipitation. Simultaneously, clouds and precipitation may not occur if the lower levels of the atmosphere do not contain sufficient moisture. Therefore, we discuss the forecasting difference between the data assimilation experiments and the control experiment with respect to temperature and the water vapor mixing ratio. Figures 6 and 7 show that the temperature simulated by the remote sensing precipitation assimilation is much lower than that simulated by the control simulation. As time progresses, the difference is further increased. The forecasting difference of the average temperature at 06:00 UTC on 21 June 2008 over the 2nd domain between the FY-2D assimilation and the control experiment is $-0.14 \mathrm{~K}$, which reaches $-2.83 \mathrm{~K}$ at 00:00 UTC on 23 June 2008. The forecasting differences of the average temperature between the TRMM assimilation and the control experiment are not too large, but are obvious. Conversely, the water vapor mixing ratio simulated by the assimilation is much higher than that simulated by the control simulation. The lower precipitation and higher water vapor mixing ratio contribute to the development of precipitation. The forecasting difference of the average vapor water mixing ratio between the FY-2D assimilation and the control experiment is $0.02 \mathrm{~g} / \mathrm{kg}$ at 06:00 UTC on 21 June 2008, which reaches $1.17 \mathrm{~g} / \mathrm{kg}$ after two days. The forecasting differences of the average vapor water mixing ratio between the TRMM assimilation and the control experiment is not so big but is also obvious.

The assimilation of the remote sensing precipitation products caused other simulated variables to be more in agreement with the observations. The biases in the relative humidity simulated in both the CTL and DA experiments were small. Moreover, the DA results yielded much higher cross-correlation coefficients, especially for FY_DA (No. 3 in blue in Figure 11). Relative humidity has a prominent positive correlation with precipitation. Therefore, improving the simulations of relative humidity can improve precipitation forecasting. Conversely, shortwave downward radiation, in particular, generally has a strong negative correlation with precipitation. Thus, improving the simulations of shortwave radiation can indirectly improve precipitation forecasting. The shortwave radiation estimates of the DA experiment (No. 6 in red and blue) are much better than those of the CTL experiment. Additionally, the cross-correlation coefficients of wind speed simulated in both the CTL and DA experiments are poor, but although the bias in DA was much less than that in the CTL experiment.

\subsection{Effect of Assimilating Remote Sensing Precipitation Products on Spin-Up Time}

Typically, a 12-24 h spin-up time is required in mesoscale NWPs to achieve optimal operation and avoid instabilities. However, efficient and time-saving forecasting is important in NWP modeling. Some studies have shown that model spin-up time can be shortened by data assimilation in the NWP models $[53,54]$. In our case study, Figures 6 and 7 show that the differences in the hydrothermal variables between the data assimilation and CTL experiments are obvious at $12 \mathrm{~h}$. Additionally, Figures 9 and 13 show that the accumulated volumes of precipitation at nine gauge sites from 00:00 UTC to 15:00 UTC on 21 June 2008, and at six HiWATER super stations from 00:00 UTC to 15:00 UTC on 1 July 2015, are different based on the estimates of various data assimilation and CTL experiments. Notably, the accumulated volumes of precipitation yielded by the CTL experiment (black lines) are much lower than those yielded by the data assimilation (green and blue lines in Figure 9, green, purple and blue lines in Figure 13), which exhibit good agreement with the observational data (red lines). In the CTL experiment, although the water vapor mixing ratio is integrated quickly using the Richardson balance equation, its initial value is zero at 00:00 UTC and requires $12 \mathrm{~h}$ to reach the real state. In the data assimilation experiments, the water vapor mixing ratio initial data are updated and 
closer to real state because the precipitation remote sensing data are assimilated into the WRF model. In practice, a $12 \mathrm{~h}$ spin-up time is very slow for weather forecasting of a few days into the future. Therefore, the spin-up time of our WRF model can be shortened by assimilation using remote sensing precipitation products.

\subsection{Influence of the Accuracy of Remote Sensing Precipitation Products on Data Assimilation Result}

By assimilating the TRMM and FY-2D precipitation products into the WRF model, both data assimilation experiments yielded better estimates of the hydrothermal variables compared to those of the CTL experiment. However, a further distinction can be observed between these two data assimilation experiments. The accumulated precipitation estimate of FY-2D (Figure $4 \mathrm{~b}$ ) is higher than that of TRMM (Figure 4a); therefore, the temperature and water vapor mixing ratio differences between the FY-2D assimilation and CTL experiments are much larger than those between the TRMM assimilation and CTL experiments at $6 \mathrm{~h}$ (first columns in Figures 6 and 7). Over time, these differences increase (right three columns in Figures 6 and 7). Furthermore, compared to the observational data in Figure 8, the accumulated volumes estimated using the FY-2D precipitation product at $24 \mathrm{~h}$ and $48 \mathrm{~h}$ are larger than those based on the TRMM data in the upper HRB. Additionally, the accumulated volumes of precipitation estimated based on the FY-2D assimilation are much higher than those yielded by the TRMM assimilation. One possible reason is that the merged TRMM 3B42V6 precipitation flux over the HRB was underestimated; some evaluations of the TRMM precipitation over the HRB have proved the underestimation [55,56]. The accumulated volumes of $6 \mathrm{~h}$ remote sensing precipitation from 00:00 UTC on 21 June 2008, based on the TRMM and FY-2D satellite-retrieved are $0.75 \mathrm{~km}^{3}$ and $0.86 \mathrm{~km}^{3}$, respectively, over the 1 st domain $\left(60 \times 60 \times 625 \mathrm{~km}^{2}\right)$. The accumulated volumes of the simulated $48 \mathrm{~h}$ precipitation from 00:00 UTC on 21 June 2008, based on the TRMM assimilation and FY-2D assimilations are $1.63 \mathrm{~km}^{3}$ and $1.75 \mathrm{~km}^{3}$, respectively, over the 2 nd domain $\left(130 \times 130 \times 25 \mathrm{~km}^{2}\right)$. Compared with the ratio of the remote sensing precipitation between the FY-2D and TRMM satellite-retrieved data, the ratio of the simulated precipitation between the FY-2D and TRMM assimilations is smaller; however, the accumulated precipitation flux difference cannot be ignored. The precipitation assimilation in the WRF model is affected greatly by the remote sensing precipitation, which can be seen as the constraint over the whole research region; finer details can be characterized by the WRF model. Therefore, accurate remote sensing precipitation products are essential for precise NWP data assimilation at the mesoscale.

At the second case study, the spatial distributions of precipitation of assimilation reflect those of remote sensing precipitation products, especially over upstream region, which can be found in Figure 12. The peak center of TRMM is located at the western upstream, the same center can be found at the TRMM assimilation simulation. The peak center of FY-2G is located at the eastern upstream, either for the FY-2G assimilation simulation. The same peak center can be found for GPM precipitation product and its assimilation simulation.

\subsection{Comparison of Measurements of Remote Sensing Precipitation Products}

In Figures 3 and 8, it can be found that the spatial patterns of TRMM 3B42V6 and FY-2D are rather different. The accumulated precipitation product on 21 June 2008 of FY-2D is much more homogenous than that of TRMM 3B42V6 over the upstream of the HRB. The possible reason is that the FY-2D precipitation product retrieved by optical and NIR sensors which has much higher spatial resolution with overestimation on precipitation, and the TRMM 3B42V6 is derived in part from radar active sensing as well as microwave sensors, which partly reflect the orography enhancement with lower spatial resolution. It is necessary to use a fusion method to merge variety precipitation data to develop a precipitation product which is better than any individual product at any given spatial or temporal location. 
In Figure 12, we can find that GPM real time remote sensing precipitation products can provide more detail info than TRMM over the upstream of the HRB, which is helpful for WRF data assimilation to yield better precipitation forecasting over complex region.

At same time, it is clear that assimilating remote sensing data into WRF model is effective and yielding better simulation, however, it is hard to say which remote sensing product is more suitable to be adopted in NWP when the case study is based on solo WRF model. Thus, in the future, it is necessary to use multiple NWPs to obtain better precipitation product at a certain region.

\section{Conclusions}

The WRF model was used to assimilate satellite precipitation products (TRMM 3B42, FY-2D series and GPM) using the 4D-Var data assimilation method to improve precipitation simulation and forecasting over complex terrain in an inland river basin. Two case studies were performed and a few experiments were included in each case study, including control simulations, TRMM data assimilation, FY series data assimilation and a GPM data assimilation. The results of these experiments were evaluated against rain gauge data and HiWATER super station data. The new approach produced more reliable and more high-resolution precipitation compared with using the model alone or the remote sensing products. The following conclusions were drawn from this study: (1) The assimilation of remote sensing precipitation products can improve the initialization of the humidity and temperature fields in the WRF model, and, therefore, yields a better precipitation simulation which can express the spatial heterogeneity caused by diverse landscape and complex terrain of an inland river basin, thereby improving the WRF forecasting ability over a complex terrain. (2) The spin-up time is shortened and precipitation forecasting is improved by assimilating remote sensing precipitation products. Therefore, assimilating remote sensing precipitation products using WRF $4 \mathrm{D}$-Var can be viewed as a positive step toward improving the accuracy and lead time of NWP models, particularly over regions with complex terrains.

Acknowledgments: This work was supported by grants from the National Natural Science Foundation of China (41471292, 91425303, and 41630856). TRMM 3B42 and GPM precipitation data were acquired from NASA's Earth Science Division and archived and distributed by the Goddard Earth Sciences (GES) Data and Information Services Center (DISC). FY-2D precipitation products were downloaded from the Chinese National Satellite Meteorological Center (NSMC). We thank Yu Liu for helping process the FY-2D data. The input data for the WRF model were obtained from the Research Data Archive (RDA), which is maintained by the Computational and Information Systems Laboratory (CISL) at the National Center for Atmospheric Research (NCAR). The original data are available from the RDA (https:/ / rda.ucar.edu) in data set ds083.2. CMA station data were downloaded from the China Meteorological Data Sharing Service System (http://cdc.cma.gov.cn). WATER data were provided by the Cold and Arid Regions Science Data Center at Lanzhou (http://westdc.westgis.ac.cn). The NCAR Command Language (NCL) (version 6.1.2) (Software) (2013) is available from the UCAR/NCAR/CISL/VETS (http:/ / dx.doi.org/10.5065/D6WD3XH5), Boulder, Colorado. NCL was used for the data analysis and graphs in this paper. We acknowledge the computing resources and time spent at the Supercomputing Center of the Cold and Arid Region Environment and Engineering Research Institute of the Chinese Academy of Sciences. The authors thank anonymous reviewers and the editor for their very helpful comments.

Author Contributions: Xiaoduo Pan and Xin Li conceived and designed the experiments; Xiaoduo Pan performed the experiments and wrote the paper; and Xin Li, Guodong Cheng, and Yang Hong contributed to discussions and revisions.

Conflicts of Interest: The authors declare no conflict of interest.

\section{References}

1. Immerzeel, W.W.; Rutten, M.M.; Droogers, P. Spatial downscaling of TRMM precipitation using vegetative response on the Iberian Peninsula. Remote Sens. Environ. 2009, 113, 362-370. [CrossRef]

2. Sorooshian, S.; AghaKouchak, A.; Arkin, P.; Eylander, J.; Foufoula-Georgiou, E.; Harmon, R.; Hendrickx, J.M.; Imam, B.; Kuligowski, R.; Skahill, B. Advanced concepts on remote sensing of precipitation at multiple scales. Bull. Am. Meteorol. Soc. 2011, 92, 1353-1357. [CrossRef]

3. Alemohammad, S.H.; McLaughlin, D.B.; Entekhabi, D. Quantifying precipitation uncertainty for land data assimilation applications. Mon. Weather Rev. 2015, 143, 3276-3299. [CrossRef] 
4. Ward, E.; Buytaert, W.; Peaver, L.; Wheater, H. Evaluation of precipitation products over complex mountainous terrain: A water resources perspective. Adv. Water Resour. 2011, 34, 1222-1231. [CrossRef]

5. Sevruk, B.; Ondrás, M.; Chvíla, B. The WMO precipitation measurement intercomparisons. Atmos. Res. 2009, 92, 376-380. [CrossRef]

6. Kidd, C. Satellite rainfall climatology: A review. Int. J. Climatol. 2001, 21, 1041-1066. [CrossRef]

7. Fritsch, J.M.; Carbone, R.E. Improving quantitative precipitation forecasts in the warm season: A USWRP research and development strategy. Bull. Am. Meteorol. Soc. 2004, 85, 955-965. [CrossRef]

8. Pan, X.; Li, X.; Cheng, G.; Li, H.; He, X. Development and evaluation of a river-basin-scale high spatio-temporal precipitation data set using the WRF model: A case study of the Heihe River Basin. Remote Sens. 2015, 7, 9230-9252. [CrossRef]

9. Wang, S.-Y.; Clark, A.J. NAM model forecasts of warm-season quasi-stationary frontal environments in the Central United States. Weather Forecast. 2010, 25, 1281-1292. [CrossRef]

10. Marécal, V.; Mahfouf, J.-F. Variational retrieval of temperature and humidity profiles from TRMM precipitation data. Mon. Weather Rev. 2000, 128, 3853-3866. [CrossRef]

11. Marécal, V.; Mahfouf, J.F. Experiments on 4D-Var assimilation of rainfall data using an incremental formulation. Q. J. R. Meteorol. Soc. 2003, 129, 3137-3160. [CrossRef]

12. Jones, T.A.; Stensrud, D.J.; Minnis, P.; Palikonda, R. Evaluation of a forward operator to assimilate cloud water path into WRF-DART. Mon. Weather Rev. 2013, 141, 2272-2289. [CrossRef]

13. Jones, T.A.; Otkin, J.A.; Stensrud, D.J.; Knopfmeier, K. Assimilation of satellite infrared radiances and doppler radar observations during a cool season observing system simulation experiment. Mon. Weather Rev. 2013, 141, 3273-3299. [CrossRef]

14. Jones, T.A.; Otkin, J.A.; Stensrud, D.J.; Knopfmeier, K. Forecast evaluation of an observing system simulation experiment assimilating both radar and satellite data. Mon. Weather Rev. 2014, 142, 107-124. [CrossRef]

15. Županski, D.; Mesinger, F. Four-dimensional variational assimilation of precipitation data. Mon. Weather Rev. 1995, 123, 1112-1127. [CrossRef]

16. Krishnamurti, T.N.; Xue, J.; Bedi, H.S.; Ingles, K.; Oosterhof, D. Physical initialization for numerical weather prediction over the tropics. Tellus A 1991, 43, 53-81. [CrossRef]

17. Krishnamurti, T.N.; Bedi, H.S.; Ingles, K. Physical initialization using SSM/I rain rates. Tellus A 1993, 45, 247-269. [CrossRef]

18. Puri, K.; Miller, M. Sensitivity of ECMWF analyses-forecasts of tropical cyclones to cumulus parameterization. Mon. Weather Rev. 1990, 118, 1709-1742. [CrossRef]

19. Treadon, R.E. Physical initialization in the NMC global data assimilation system. Meteorol. Atmos. Phys. 1996, 60, 57-86. [CrossRef]

20. Tsuyuki, T. Variational data assimilation in the tropics using precipitation data. Part III: Assimilation of SSM/I precipitation rates. Mon. Weather Rev. 1997, 125, 1447-1464. [CrossRef]

21. Bauer, P.; Ohring, G.; Kummerow, C.; Auligne, T. Assimilating satellite observations of clouds and precipitation into NWP models. Bull. Am. Meteorol. Soc. 2011, 92, ES25-ES28. [CrossRef]

22. Hou, A.Y.; Zhang, S.Q.; Reale, O. Variational continuous assimilation of TMI and SSM/I rain rates: Impact on GEOS-3 hurricane analyses and forecasts. Mon. Weather Rev. 2004, 132, 2094-2109. [CrossRef]

23. Kumar, P.; Kishtawal, C.; Pal, P. Impact of satellite rainfall assimilation on weather research and forecasting model predictions over the Indian region. J. Geophys. Res. Atmos. 2014, 119, 2017-2031. [CrossRef]

24. Lopez, P. Direct 4D-Var assimilation of NCEP stage IV radar and gauge precipitation data at ECMWF. Mon. Weather Rev. 2011, 139, 2098-2116. [CrossRef]

25. Pu, Z.; Tao, W.-K.; Braun, S.; Simpson, J.; Jia, Y.; Halverson, J.; Olson, W.; Hou, A. The impact of TRMM data on mesoscale numerical simulation of super typhoon Paka. Mon. Weather Rev. 2002, 130, 2448-2458. [CrossRef]

26. Zou, X.; Kuo, Y. Rainfall assimilation through an optimal control of initial and boundary conditions in a limited-area mesoscale model. Mon. Weather Rev. 1996, 124, 2859-2882. [CrossRef]

27. Hu, Y.Q.; Gao, Y.X.; Wang, J.M.; Ji, G.L.; Shen, Z.B.; Cheng, L.S.; Cheng, J.Y.; Li, S.Q. Some achievements in scientific research during HEIFE. Plateau Meteorol. 1994, 13, 225-236. (In Chinese)

28. Li, X.; Li, X.; Li, Z.; Ma, M.; Wang, J.; Xiao, Q.; Liu, Q.; Che, T.; Chen, E.; Yan, G.; et al. Watershed allied telemetry experimental research. J. Geophys. Res. Atmos. 2009, 114, D22103. [CrossRef] 
29. Li, X.; Cheng, G.; Liu, S.; Xiao, Q.; Ma, M.; Jin, R.; Che, T.; Liu, Q.; Wang, W.; Qi, Y.; et al. Heihe Watershed Allied Telemetry Experimental Research (HiWATER): Scientific objectives and experimental design. Bull. Am. Meteorol. Soc. 2013, 94, 1145-1160. [CrossRef]

30. Pan, X.; Tian, X.; Li, X.; Xie, Z.; Shao, A.; Lu, C. Assimilating Doppler radar radial velocity and reflectivity observations in the weather research and forecasting model by a proper orthogonal-decomposition-based ensemble, three-dimensional variational assimilation method. J. Geophys. Res. Atmos. 2012, 117, D17113. [CrossRef]

31. Skamarock, W.C.; Klemp, J.B.; Dudhia, J.; Gill, D.O.; Barker, D.M.; Wang, W.; Powers, J.G. A Description of the Advanced Research WRF Version 3; NCAR Technical Note; 2008; Mesoscale and Microscale Meteorology Division: Boulder, CO, USA; p. 475.

32. Hong, S.-Y.; Dudhia, J.; Chen, S.-H. A revised approach to ice microphysical processes for the bulk parameterization of clouds and precipitation. Mon. Weather Rev. 2004, 132, 103-120. [CrossRef]

33. Kain, J.S. The Kain-Fritsch convective parameterization: An update. J. Appl. Meteorol. 2004, 43, $170-181$. [CrossRef]

34. Hong, S.-Y.; Noh, Y.; Dudhia, J. A new vertical diffusion package with an explicit treatment of entrainment processes. Mon. Weather Rev. 2006, 134, 2318-2341. [CrossRef]

35. Dudhia, J. Numerical study of convection observed during the winter monsoon experiment using a mesoscale two-dimensional model. J. Atmos. Sci. 1989, 46, 3077-3107. [CrossRef]

36. Mlawer, E.J.; Taubman, S.J.; Brown, P.D.; Iacono, M.J.; Clough, S.A. Radiative transfer for inhomogeneous atmospheres: RRTM, a validated correlated-k model for the longwave. J. Geophys. Res. Atmos. 1997, 102, 16663-16682. [CrossRef]

37. Barker, D.M.; Huang, W.; Guo, Y.R.; Bourgeois, A.J.; Xiao, Q.N. A three-dimensional variational data assimilation system for MM5: Implementation and initial results. Mon. Weather Rev. 2004, 132, 897-914. [CrossRef]

38. Barker, D.; Huang, X.-Y.; Liu, Z.; Auligné, T.; Zhang, X.; Rugg, S.; Ajjaji, R.; Bourgeois, A.; Bray, J.; Chen, Y.; et al. The weather research and forecasting model's community variational/ensemble data assimilation system: WRFDA. Bull. Am. Meteorol. Soc. 2012, 93, 831-843. [CrossRef]

39. Huang, X.-Y.; Xiao, Q.; Barker, D.M.; Zhang, X.; Michalakes, J.; Huang, W.; Henderson, T.; Bray, J.; Chen, Y.; Ma, Z. Four-dimensional variational data assimilation for WRF: Formulation and preliminary results. Mon. Weather Rev. 2009, 137, 299-314. [CrossRef]

40. Chu, K.; Xiao, Q.; Liu, C. Experiments of the WRF three-/four-dimensional variational (3/4DVAR) data assimilation in the forecasting of Antarctic cyclones. Meteorol. Atmos. Phys. 2013, 120, 145-156. [CrossRef]

41. Hascoët, L.; Pascual, V. TAPENADE 2.1 User's Guide; Rapport Technique 300; INRIA: Sophia Antipolis, France, 2004.

42. Zhang, X.; Huang, X.-Y.; Pan, N. Development of the upgraded tangent linear and adjoint of the weather research and forecasting (WRF) model. J. Atmos. Ocean. Technol. 2013, 30, 1180-1188. [CrossRef]

43. Zhang, X.; Huang, X.-Y.; Liu, J.; Poterjoy, J.; Weng, Y.; Zhang, F.; Wang, H. Development of an efficient regional four-dimensional variational data assimilation system for WRF. J. Atmos. Ocean. Technol. 2014, 31, 2777-2794. [CrossRef]

44. Descombes, G.; Auligné, T.; Vandenberghe, F.; Barker, D.; Barre, J. Generalized background error covariance matrix model (GEN_BE v2.0). Geosci. Model Dev. 2015, 8, 669-696. [CrossRef]

45. Rabier, F.; McNally, A.; Andersson, E.; Courtier, P.; Unden, P.; Eyre, J.; Hollingsworth, A.; Bouttier, F. The ECMWF implementation of three-dimensional variational assimilation (3D-Var). II: Structure functions. Q. J. R. Meteorol. Soc. 1998, 124, 1809-1829. [CrossRef]

46. Wang, J.; Li, J. A four-dimensional scheme based on singular value decomposition (4DSVD) for chaotic-attractor-theory-oriented data assimilation. J. Geophys. Res. 2009, 114, D02114. [CrossRef]

47. Parrish, D.F.; Derber, J.C. The national meteorological center's spectral statistical-interpolation analysis system. Mon. Weather Rev. 1992, 120, 1747-1763. [CrossRef]

48. Wilheit, T.; Hutchison, K. Water vapour profile retrievals from SSM/T-2 data constrained by infrared-based cloud parameters. Int. J. Remote Sens. 1997, 18, 3263-3277. [CrossRef]

49. Huffman, G.J.; Bolvin, D.T.; Nelkin, E.J.; Wolff, D.B.; Adler, R.F.; Gu, G.; Hong, Y.; Bowman, K.P.; Stocker, E.F. The TRMM multisatellite precipitation analysis: Quasi-global, multiyear, combined-sensor precipitation estimates at fine scales. J. Hydrometeorol. 2007, 8, 38-55. [CrossRef] 
50. Hong, Y.; Yuan, D.-H.; Liu, Y.-Q.; Gao, P. Dynamical estimation of short time precipitation from satellite cloud parameters. Meteor. Sci. Technol. 2011, 39, 266-271.

51. Robinson, A.R.; Lermusiaux, P.F.J. An Overview of Data Assimilation; Harvard Reports in Physical/ Interdisciplinary Ocean Science; No. 62; The Division of Engineering and Applied Sciences: Harvard University, Cambridge, MA, USA, 2000.

52. Skofronick-Jackson, G.; Petersen, W.A.; Berg, W.; Kidd, C.; Stocker, E.; Kirschbaum, D.B.; Kakar, R.; Braun, S.A.; Huffman, G.J.; Iguchi, T.; et al. The global precipitation measurement (GPM) mission for science and society. Bull. Am. Meteorol. Soc. 2016. [CrossRef]

53. Qin, Y.; Gong, J.; Li, Z.; Sheng, R. Assimilation of Doppler radar observations with an ensemble square root filter: A squall line case study. J. Meteorol. Res. 2014, 28, 230-251. [CrossRef]

54. Shao, A.; Qiu, C.; Niu, G.-Y. A piecewise modeling approach for climate sensitivity studies: Tests with a shallow-water model. J. Meteorol. Res. 2015, 29, 735-746. [CrossRef]

55. Peng, B.; Shi, J.; Ni-Meister, W.; Zhao, T.; Ji, D. Evaluation of TRMM multisatellite precipitation analysis (TMPA) products and their potential hydrological application at an arid and semiarid basin in China. IEEE J. Sel. Top. Appl. Earth Obs. Remote Sens. 2014, 7, 3915-3930. [CrossRef]

56. Wu, X.; Yang, M.; Wu, H.; Wu, Y.; Wang, X. Verifying and applying the TRMM TMPA in Heihe River Basin. J. Glaciol. Geocryol. 2013, 35, 310-319.

(c) 2017 by the authors. Licensee MDPI, Basel, Switzerland. This article is an open access article distributed under the terms and conditions of the Creative Commons Attribution (CC BY) license (http://creativecommons.org/licenses/by/4.0/). 